\section{Veterinaria México OA}

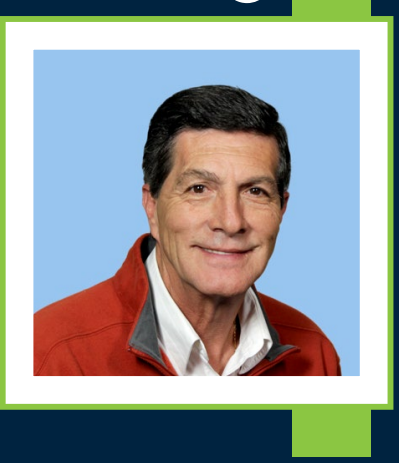

\section{Luis Ocampo Camberos}

El Dr. Luis Ocampo Camberos egresó de la Facultad de Medicina Veterinaria y Zootecnia en 1970 y en 1975 obtuvo la Maestría en Ciencias en Farmacología y Toxicología en la Universidad de California, Davis, EUA. Ha liderado proyectos de investigación en inocuidad alimenticia al evaluar los efectos para la salud pública del uso de la furazolidona en el pollo productor de carne, logrando además una notable vinculación con la industria farmacéutica mexicana y con otras instituciones como el Instituto Nacional de Salud Pública. Es autor de 10 libros de texto y de 210 artículos científicos. En 2009 fue nombrado Profesor Emérito de la Universidad Nacional Autónoma de México.

*Profesor Emérito de la Universidad Nacional Autónoma de México

Departamento de Fisiología y Farmacología, Facultad de Medicina Veterinaria y Zootecnia, Universidad Nacional Autónoma de México. México

Autor para correspondencia:

Correo electrónico:

farmac@unam.mx

Sumano López H, Lizárraga Madrigal I, Ocampo Camberos L, Obregón Jurgens K. Reacciones adversas de los fármacos en los equinos. Veterinaria México. 2000;31(4):329-54.

Publicado: 2020-09-30

(c) Derechos de autor:

Héctor Sumano López et al. 2020

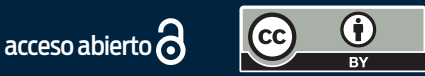

Distribuido bajo una Licencia Creative Commons Atribución 4.0 Internacional (CC-BY 4.0)
Veterinaria

\title{
Reacciones adversas de los fármacos en los equinos
}

Héctor Sumano López

Ignacio Lizárraga Madrigal

Luis Ocampo Camberos*

Karina Obregón Jurgens

\section{Abstract}

Knowledge of newly identified and well established adverse drug reactions (ADR) in horses will limit the amount of iatrogenic medical interventions, and will hasten recovery of equine patients from a given disease. ADRs can occur at any given time and under a great variety of clinical settings. However, if clinicians reinforce their continuous education on this subject, and become aware of the underlying mechanisms that induce ADRs they can both administer drugs with a greater margin of safety and certainly, predict the likelyhood of the presentation of ADRs. In turn, clinicians will be capable of suggesting the use of an alternative drug. The aim of this review is to bring up-to-date the reported knowledge on ADRs in horses, identifying the modus operandi, the incidence, the possible extension of the organic damage and when possible, the adequate treatment. It is our hope that busy equine practitioners and their patients will benefit from this retrospective analysis of ADRs in horses. This review also attempts to encourage practitioners to report new ADRs that will enrich the knowledge of pharmacological peculiarities of drugs used in equine practice.

Keywords: Adverse drug reactions; Horses; Drug-interactions; Toxic-effects

Cite this as:

Sumano López H, Lizárraga Madrigal I, Ocampo Camberos L, Obregón Jurgens K.

Reacciones adversas de los fármacos en los equinos. Veterinaria México OA. 2020:7(3).

doi:10.22201/fmvz.24486760e.2020.3.925. 


\section{Resumen}

El conocimiento de las reacciones adversas a los fármacos (RAF), identificadas recientemente o ya conocidas de antemano, limita necesariamente la ocurrencia de iatrogenias y facilita la pronta recuperación de los pacientes equinos. Las RAF pueden ocurrir en cualquier momento y bajo una gran variedad de situaciones clínicas. Sin embargo, si los clínicos mantienen un programa de actualización en este tema en particular e identifican los mecanismos de acción que propiciaron una RAF, podrán administrar los fármacos con mayor certeza y margen de seguridad. Asimismo, los clínicos predecirán la presentación de algunas RAF y sugerirán el uso de un fármaco alternativo. Los objetivos de este estudio retrospectivo fueron la actualización del conocimiento sobre las RAF, identificación del modus operandi, incidencia, magnitud del daño que se pueda generar y, cuando es posible, el tratamiento adecuado. Se espera que de esta revisión se beneficien tanto los clínicos como sus pacientes equinos, pero adicionalmente se pretende favorecer el informe de hallazgos de RAF, con el fin de hacer cada vez más completo el conocimiento farmacológico de los medicamentos usados en la clínica de caballos.

Palabras clave: Reacciones adversas a los fármacos; Caballos; Interacciones medicamentosas; Efectos tóxicos 


\section{Introducción}

Debe distinguirse entre iatrogenia esto es, daño inducido a un paciente por ignorancia o negligencia médica, y la presentación de una reacción adversa (RA). Casi cualquier medicamento puede inducir una RA. Las hay de todos tipos: las relacionadas con el modus operandi del fármaco, las que están ligadas a la dosis y concentración plasmática alcanzada (reacciones tipo A), y las reacciones debidas a otro efecto del medicamento, no relacionado con su mecanismo de acción directamente, sino con un efecto mejor descrito como paradójico (reacciones tipo B). ${ }^{1}$ Las RA pueden generarse en un paciente por muchas razones (raza, edad, estado fisiológico, presencia de otros medicamentos, susceptibilidad individual, etc.); por ejemplo, una RA tipo A se presenta como consecuencia de la aplicación de una sobredosis de gentamicina a un caballo, al que induce daño renal. No obstante, dada la variabilidad de la vida media de la gentamicina en caballos, se puede inducir daño renal a un paciente susceptible, con dosis supuestamente adecuadas. Una RA tipo B se puede generar si se aplica gentamicina a un caballo deshidratado, y posterior a una anestesia. En estos casos, es posible que se presente un bloqueo neuromuscular y parálisis flácida de consecuencias fatales. En ambas instancias es obligación del veterinario reconocer la RA, distinguirla de una iatrogenia y, en lo posible, informarla en la literatura científica. Muchas RA se derivan de interacciones indeseables y pueden considerarse como otro rubro; pero en esta compilación no se hará la distinción.

En este escrito se ha considerado como objetivo primario: presentar un estudio retrospectivo de las posibles RA (A y B) que afectan a los equinos, con el propósito de actualizar al especialista al respecto, para que en lo posible las evite. En las Figuras 1-4 se cuantifican, por grupos terapéuticos, las RA descritas para equinos en un estudio en 1994.

\section{Tranquilizantes}

\section{Agonistas $\alpha_{2}$ adrenérgicos}

Se pueden observar efectos agonistas cardiacos y vasculares $\alpha_{1}$ y $\alpha_{2}$ después de la administración intravenosa (IV) de xilazina o detomidina. Al principio, aumenta la presión sanguínea, como resultado de este agonismo doble. La respuesta se da después de 15 segundos de haber administrado el fármaco y dura poco menos de 15 minutos, ${ }^{2,3}$ pero después disminuye debido a la estimulación vagal y a los efectos persistentes sobre los receptores $\mathrm{a}_{2}$ en el sistema nervioso central (SNC). ${ }^{2,4-8}$

La xilazina ha sido descrita como agonista parcial de receptores $\alpha_{2}$-adrenérgicos en la periferia, ${ }^{9}$ por lo que puede inducir alteraciones cardiovasculares importantes. Induce bloqueo atrioventricular (AV) de primero y, en ocasiones de segundo grado, , 4,5,10-15 que en teoría pueden causar colapso cardiovascular, específicamente si se usa una anestesia con halotano, ${ }^{16}$ o en pacientes susceptibles. Estos efectos se observan con mayor frecuencia cuando se administra por vía IV y rara vez con la administración intramuscular (im). ${ }^{17}$ Hay disminución de la demanda de oxígeno por el miocardio y del flujo sanguíneo coronario. ${ }^{18}$ Pueden 
llegar a aumentar la isquemia digital, ${ }^{19}$ por lo que no deben considerarse como opción en el tratamiento de la laminitis. ${ }^{20}$ Los agonistas $\alpha 2$-adrenérgicos disminuyen la resistencia vascular y el consumo de oxígeno en el tubo intestinal. ${ }^{21,22}$ Clarke et al. ${ }^{23}$ observaron disminución del flujo sanguíneo arterial del colon. Puede haber disminución en la frecuencia respiratoria, el volumen corriente y la concentración parcial de oxígeno arterial. ${ }^{2,11,24,25}$ Sin embargo, Hubbell y Muir ${ }^{5}$ encontraron que el volumen corriente aumenta de manera refleja a la disminución de la frecuencia respiratoria en caballos conscientes, mientras que disminuye en caballos anestesiados. Los cambios cardiorespiratorios son transitorios (desaparecen en 1-2 horas) y dependen de la dosis. ${ }^{26}$ Estos efectos pueden ser aditivos con la administración repetida. La sobredosis (más de $2 \mathrm{mg} / \mathrm{kg}$ ) induce disnea, recumbencia y muerte con o sin signos extrapiramidales (movimientos de carrera en decúbito lateral), debido a colapso cardiovascular. ${ }^{27}$ Aunque existen informes de muertes por la administración de xilazina ${ }^{21,28}$ y por la combinación de detomidina con sulfas-trimetroprim, ${ }^{29}$ en ambas instancias, no se han podido esclarecer los mecanismos farmacodinámicos responsables de estos casos, si es que los hay. Se sabe que la administración intraarterial de xilazina puede producir excitación, colapso, convulsiones, rigidez muscular y a menudo muerte súbita. ${ }^{17,30,31}$ Para producir una analgesia caudal y reducir los efectos cardiovasculares que se observan con la administración Iv, la xilazina se ha utilizado por vía epidural. ${ }^{2,14}$ Sin embargo, se ha observado que el uso de la mezcla xilazina-lidocaína para analgesia caudal, induce un efecto demasiado intenso con pérdida de la función motora de los miembros pelvianos, por lo que es necesaria la anestesia general para evitar que el paciente se lesione por el bloqueo motor completo que se refleja en ataxia durante varias horas. ${ }^{32}$

La detomidina por vía epidural induce un efecto de sedación profunda, ataxia, depresión cardiovascular, sudoración y diuresis, y por vía parenteral, comparte algunos de los efectos de bloqueo cardiaco que induce la xilazina. ${ }^{33} \mathrm{Con}$ la administración de detomidina se observa disminución en la concentración de catecolaminas plasmáticas, pero no del cortisol, lo que puede indicar que se induce una reducción de la actividad simpático adrenal. ${ }^{34}$ Un caso similar es la romifidina (otro agonista $\alpha_{2}$ ) que, a una dosis terapéuticas, puede inducir colapso cardiovascular (hipertensión seguida de hipotensión severa) con temblores musculares y depresión respiratoria. ${ }^{4}$

Los agonistas $\alpha_{2}$ adrenérgicos pueden ocasionar ataxia, ${ }^{2,15}$ la romifidina la produce en menor grado ${ }^{35}$ que la medetomidina. ${ }^{36}$ Se puede presentar una marcada relajación de los cartílagos nasales y de los músculos laríngeos, lo que ocasiona, en algunos casos, un ruido característico; ${ }^{2,5}$ además puede haber supresión del reflejo tusígeno ${ }^{6}$ y una disminución en la velocidad de depuración mucociliar. ${ }^{37}$ Otros efectos pueden ser disminución de la presión intracraneana, ${ }^{5}$ hiperglicemia, ${ }^{38,39}$ hipoinsulinemia, ${ }^{17,39}$ incremento transitorio de ADH en plasma, ${ }^{17}$ aumento de la diuresis, ${ }^{2,5,17,38,39}$ glucosuria, ${ }^{17}$ aumento de la excreción urinaria de $\mathrm{Na}+,{ }^{5} \mathrm{~K}+$ y Cl-,${ }^{17}$ hipotermia en potros, ${ }^{2}$ disminución transitoria del flujo san- 
guíneo en el músculo esquelético, ${ }^{40}$ disminución de la motilidad intestinal ${ }^{5,22,41}$ y del esófago. ${ }^{42}$ Aún no se precisa el impacto clínico de estas RA.

La mezcla quinalbarbitona (barbitúrico)-cinchocaína (anestésico local) produce eutanasia en forma suave y en un periodo de tres minutos; sin embargo, cuando se premedica al caballo con detomidina, xilazina o romifidina ( $\alpha 2$-adrenérgicos) y butorfanol (analgésico narcótico), hay retardo del colapso y la eutanasia, con actividad muscular exacerbada y jadeos, por lo que sólo se recomienda la eutanasia en este caso en particular con estos fármacos, cuando no existe otra opción al alcance. ${ }^{35}$

\section{Fenotiacínicos}

Los fenotiacínicos como el clorhidrato de promacina y la acetilpromacina, pueden causar hipotensión y taquicardia refleja transitorias según la dosis, y estos cambios pueden persistir en caballos que se encuentren en situaciones de estrés, excitación o choque, ya que las concentraciones sanguíneas de catecolaminas serán elevadas y favorecerán estas condiciones transitorias. ${ }^{24}$ Además, puede haber secuestro sanguíneo por vasodilatación periférica (causada por bloqueo de receptores $\alpha_{1}$ adrenérgicos y estimulación $\left.\beta\right)^{2,24,43}$ y sudoración profusa, lo cual disminuye el flujo sanguíneo renal y hepático con el consecuente desarrollo de choque. ${ }^{24,44,45}$ Los candidatos predecibles a un choque por fenotiacínicos son, en su mayoría, caballos viejos, sujetos bajo condiciones de estrés, excitados o con disminución de volumen plasmático. ${ }^{5}$ Estas crisis se pueden tratar por medio de la administración IV de expansores plasmáticos o fluidos isotónicos. ${ }^{5}$ Los fenotiacínicos pueden ocasionar disminución en el hematócrito y en las proteínas plasmáticas totales, posiblemente por secuestro a nivel esplénico. ${ }^{46}$ La propionilpromacina (fenotiacínico), al utilizarse como preanestésico en anestesia con halotano, ocasionó mayor hipotensión sistólica y problemas locomotores posoperatorios en comparación con la xilazina. ${ }^{47}$ Cuando se administra acepromacina por vía oral se ven menos afectados los parámetros de presión arterial media, frecuencia cardiaca y respiratoria y cuenta hemática, en comparación con la administración IV. ${ }^{48}$ Aunque los fenotiacínicos alteran la sensibilidad del centro respiratorio al $\mathrm{CO}_{2}$, los cambios en el sistema respiratorio parecen ser mínimos, ya que hay una compensación entre la disminución de la frecuencia respiratoria y un aumento del volumen corriente. ${ }^{5,49}$

El tiempo de espera para que se presenten los efectos por fenotiacínicos es impredecible. Puede requerirse 20 minutos para que se inicien los primeros signos, y de 45 a 60 minutos para que su efecto sea completo. ${ }^{5}$ El grado de sedación es variable; ${ }^{24}$ a menudo con inadecuada tranquilización y ataxia. ${ }^{6}$ Algunos signos de tranquilización persisten hasta por seis horas. No hay antagonistas específicos. ${ }^{5}$ Los fenotiacínicos inducen protrusión peneana ${ }^{2,50}$ que puede llegar a dificultar el manejo. En particular se ha relacionado el clorhidrato de propiopromacina con relajación irreversible del conjunto de músculos retractores del pene. Aunque esto ocurre ocasionalmente, de suceder, hace que el caballo quede inutilizado. Por otro lado, la protusión peneana se resuelve en un periodo de 2-10 horas y a menudo es el único signo remanente de tranquilización en caballos 
machos cuando se usa acepromacina o clorhidrato de promacina. La incidencia patológica de parálisis persistente del músculo retractor del pene es baja y su etiología es incierta. ${ }^{6,26} \mathrm{La}$ administración oral de acepromacina $(0.5 \mathrm{mg} / \mathrm{kg})$ ocasiona efectos menos pronunciados en el prolapso peneano, en comparación con la administración IV $(0.1 \mathrm{mg} / \mathrm{kg})$, por lo que se ha postulado que las elevadas concentraciones plasmáticas del fármaco después de la administración IV pueden ser las responsables de este efecto. ${ }^{48}$

En caballos son escasos los efectos colaterales a nivel de SNC por fenotiacínicos. Pueden ocasionar respuestas extrapiramidales después de la administración de flufenacina, aunque en la mayoría de los casos los signos desaparecen sin necesidad de recurrir a tratamiento alguno. No obstante, se ha informado del uso exitoso de difenhidramina o fenobarbital. ${ }^{51,52}$ Este efecto puede deberse al bloqueo excesivo de la vía dopaminérgica en la sustancia nigra y en el ganglio estriado. ${ }^{51}$ Está contraindicada la administración de fenotiacínicos a caballos que presentan convulsiones, ya que disminuyen el umbral de excitación neuronal. ${ }^{2,5}$

\section{Analgésicos narcóticos}

La administración única de analgésicos narcóticos (etorfina, fentanilo, meperidina, metadona, morfina) está asociada frecuentemente a estimulación muscular y del SNC. 2,5,25 Hay hiperactividad manifestada por movimientos circulares repetitivos con reposo ocasional y cambios de dirección; si hay alimento, algunos caballos lo mordisquean, pero no lo tragan. A dosis altas (más de $0.5 \mathrm{mg} / \mathrm{kg}$ ) hay temblores, ataxia, recumbencia y hasta depresión del SNC. También se ha observado un trote coordinado sin moverse de un solo lugar. ${ }^{53}$ La metadona, un análogo sintético de la morfina, no tiene estos efectos estimulantes. ${ }^{15}$ Hay hipersensibilidad a los estímulos visuales y auditivos. ${ }^{2}$

La severidad de la depresión respiratoria ( $v g$., fentanilo, etorfina) producida por los analgésicos narcóticos (excepto la meperidina) varía con el grado de excitación y con los efectos respiratorios que produzca la administración concomitante de otros fármacos. ${ }^{2,5}$ Los efectos cardiovasculares incluyen aumento de la frecuencia cardiaca, de la presión arterial media y del gasto cardiaco, los cuales persisten durante 5-60 minutos. ${ }^{2}$ Puede ser contraproducente la utilización de analgésicos narcóticos en algunos casos de cólico, ya que amén de enmascarar los signos clínicos de dolor, disminuyen de manera profunda y prolongada la actividad propulsiva del intestino. Este efecto no se observa con el butorfanol. ${ }^{5}$

\section{Analgésicos que actúan en receptores opiáceos $\mu$}

Aun a dosis analgésicas se puede observar estimulación simpática y del SNC.,15,53 Estos analgésicos catecolaminas endógenas (noradrenalina, adrenalina y dopamina). ${ }^{53} \mathrm{El}$ fentanilo incrementa la frecuencia cardiaca y respiratoria, produce midriasis y una ligera hipertermia, ${ }^{54}$ además de aumentar la actividad locomotora espontánea. ${ }^{15,54-56}$ Esta respuesta locomotora es más fuerte con el análogo carfentanilo, seguido del 3-metilfentanilo, el sulfentanilo, el metilfentanilo, el alfentanilo y el fentanilo. ${ }^{57-59} \mathrm{Al}$ administrar carfentanilo a un caballo premedicado con xilazina, se observó ataxia, inquietud, presión de la cabeza, recumbencia, fascicu- 
laciones musculares, movimientos de carrera, sudoración, rigidez de miembros posteriores, rigidez y arqueamiento del cuello, taquicardia, hipertensión, hipertermia, expulsión de líquido serosanguinolento por ollares, hemoconcentración, acidosis metabólica moderada y taquipnea. ${ }^{8}$ Es importante resaltar que no todos los analgésicos narcóticos con acción en receptores $\mu$ producen excitación en todos los caballos en todos los casos. Hay una variación individual en la respuesta; 53 sin embargo, con la etorfina, aun cuando se administra previa tranquilización, el caballo no está exento de presentar excitación locomotora. ${ }^{60,61}$ Además puede ocasionar taquicardia severa, aumento del tono muscular, toxemia, hipercarpnia e hipertermia. ${ }^{15} \mathrm{Al}$ administrar oximorfona a caballos y luego someterlos a ejercicio submáximo, se observó una taquicardia mayor y más duradera durante el calentamiento y el recorrido de una milla en tres minutos, en comparación con el grupo testigo. ${ }^{8}$

Muir ${ }^{6}$ menciona que el fentanilo puede producir reacciones de hipersensibilidad a estímulos visuales, auditivos y táctiles. Esto último también lo menciona Kamerling, ${ }^{53}$ quien los define como respuestas exacerbadas a los estímulos ambientales. Además se ha observado sudoración, hipertermia, midriasis, taquicardia dependiente de la dosis y taquipnea. ${ }^{55}$ Con la administración IV de meperidina se ha observado hiperestesia, fasciculaciones musculares, sudoración profusa, dilatación de pupilas y lagrimeo, posiblemente por una liberación asociada de histamina. ${ }^{62}$

Cuando se administran a dosis bajas, los analgésicos narcóticos que actúan sobre receptores $\mu$ producen pocos efectos sobre las variables cardiovasculares y pulmonares y en los gases sanguíneos. ${ }^{6}$ Sin embargo, a dosis para ocasionar inmovilización, pueden producir depresión cardiaca y respiratoria; en el intestino inducen un aumento de los movimientos de segmentación y disminución de la actividad peristáltica propulsiva. Esto se manifiesta por defecación inicial, seguida por constipación de grado variable con heces secas. ${ }^{6}$ También estimulan la liberación de hormona antidiurética (ADH) e inhiben la liberación de hormonas adenocorticotróficas y gonadotróficas. Así pueden modificar el estro de la yegua. ${ }^{6}$

\section{Analgésicos que actúan en receptores opiáceos kappa y delta}

Los analgésicos narcóticos que actúan sobre receptores opiaceos no siempre producen estimulación locomotora. ${ }^{63}$ Sin embargo, por medio de estudios neurológicos, Gasthuys et al. ${ }^{64}$ encontraron que el butorfanol $(0.04 \mathrm{mg} / \mathrm{kg}$ o más) produjo estimulación del SNC en caballos. Esto último concuerda con lo registrado por Kamerling et al., ${ }^{65}$ quienes lo observaron con una dosis de $0.2 \mathrm{mg} /$ kg. Matthews y Lindsay ${ }^{66}$ y Nolan et al. ${ }^{67}$ encontraron el mismo efecto, pero en ponis. Posiblemente estos efectos de estimulación se deban a la interacción del butorfanol con los receptores. ${ }^{53}$ Se cree que estos receptores están asociados con signos de excitación, aumento en la locomoción, tolerancia a los analgésicos narcóticos, midriasis y taquicardia. ${ }^{6}$ El PD117302 también ocasionó estimulación

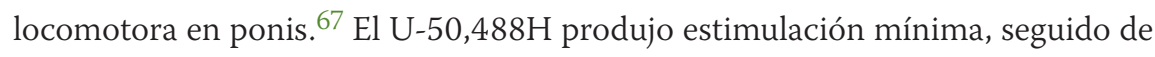
la etilquetazocina y del fentanilo. 68,69 
El butorfanol incrementa la frecuencia cardiaca y la presión arterial. ${ }^{53}$ Produce pocos efectos sobre los sonidos intestinales, el tiempo del transito intestinal o la frecuencia de defecación, ${ }^{6}$ a diferencia de los efectos de los analgésicos narcóticos que actúan sobre receptores $\mu$.

\section{Otros analgésicos}

El hidrato de cloral se usa en preparado junto con sulfato de magnesio y pentobarbital, sólo por vía IV y en concentraciones menores al 12\%, ya que es extremadamente irritante para los tejidos. Puede, además, producir ataxia severa aun a dosis bajas. $^{2}$

La azaperona reduce el valor del hematócrito, ${ }^{70}$ posiblemente por secuestro esplénico. Además, puede producir cambios de comportamiento y aun exitación, ${ }^{71}$ por lo que su uso clínico no está difundido.

La reserpina requiere de un periodo muy largo para observar su acción; sin embargo, la duración de sus efectos persiste por mucho tiempo (hasta 10 días). ${ }^{26}$ Se ha informado de depresión inicial seguida de cambios súbitos en el comportamiento que, muchas veces, pueden ser únicamente detectados por quienes conocen el comportamiento normal del caballo. ${ }^{26}$

El diazepan no es útil para producir inmovilización con el caballo de pie, ya que el grado de sedación no es suficiente y al incrementar la dosis $(0.15-0.2 \mathrm{mg} / \mathrm{kg}$ IV) se produce relajación muscular profunda, ataxia y recumbencia. $2,5,72$

\section{Anestésicos}

Todos los anestésicos generales alteran el aparato cardiopulmonar, aunque en diferentes grados, no importa cuál sea la técnica o protocolo anestésico utilizado. ${ }^{5}$ Esto último se debe a la actividad depresora de los anestésicos en el sistema cardiorrespiratorio y por la posición lateral o dorsal que guarda el caballo durante el procedimiento anestésico, lo que induce una insuficiencia de la relación ventilación-perfusión. Bajo recumbencia lateral se reduce la perfusión intersticial del músculo bíceps femoral $(19.7 \pm 0.15 \mathrm{~mm} \mathrm{Hg}$ ) y disminución del pH intersticial (de $7.07 \pm 0.3$ a $6.73 \pm 0.21$ ) con cambios fermentativos después de 45-150 minutos de anestesia. ${ }^{73}$ También existen informes de parálisis laríngea asociada con anestesia general, ${ }^{28}$ atelectasia, ${ }^{74}$ disminución de la respuesta inmune y de la fertilidad ${ }^{75}$ por modificaciones endocrinas no bien determinadas.

\section{Barbitúricos}

Inducen depresión dependiente de la dosis y se observan efectos que inician con calma, somnolencia, inconsciencia, anestesia y pueden llegar a inducir coma y muerte. Dado que tienen un índice terapéutico bajo, a menudo no se logra actividad anticonvulsiva sin ocasionar depresión general. Paradójicamente, se puede producir excitación con dosis subanestésicas; ${ }^{26}$ en este sentido, se recomienda su uso en caballos sólo como anticonvulsivos, inductores de la anestesia o agentes eutanásicos. 


\section{Otros anestésicos}

\section{Gliceril guayacol éter}

Se ha comentado que a concentraciones mayores del $12 \%$ puede producir hemólisis. ${ }^{76} \mathrm{Al}$ administrarlo por catéter IV y en concentraciones del 10\%, se observaron trombos en venas yugulares en $100 \%$ de los casos (7 caballos), mientras que esto sólo se observó en uno de cinco caballos que recibieron el medicamento a una concentración del 5\%. Es evidente, entonces, que deben observarse precauciones en caballos con alto riesgo de trombosis o tromboflebitis. ${ }^{77}$ Dickson et al. ${ }^{78}$ también registraron tromboflebitis en el sitio de inyección. La sobredosis se observa como rigidez muscular, hipotensión y respiración con apneas transitorias que pueden progresar a paro respiratorio que casi siempre se acompaña de paro cardiaco, ${ }^{5,33}$

\section{Ciclohexilaminas}

La ketamina debe administrarse siempre después de haber logrado sedación con algún otro fármaco, pues produce excitación, ${ }^{79}$ al igual que patrones respiratorios con apneas, los cuales son arrítmicos y producen pocos cambios en la presión parcial de oxígeno arterial y en la retención de $\mathrm{CO}_{2} \cdot{ }^{5} \mathrm{Si}$ la ketamina es readministrada más de una vez para prolongar el tiempo de anestesia, se corre el riesgo de disminuir la calidad de la recuperación, ocasionar rigidez muscular y hasta convulsiones. ${ }^{80}$ Igualmente, si se combina con xilazina no hay muy buena relajación muscular. ${ }^{5,81}$ Cuando se hace con detomidina se observa recuperación de menor calidad y con mayor grado de incoordinación, que cuando se combina con xilazina. ${ }^{79,81,82}$

El uso de xilazina junto con la mezcla de tiletamina (ciclohexilamina)-zolacepam (benzodiacepina) produce mayor relajación muscular y depresión respiratoria, 5,81 pero la recuperación del paciente a la anestesia cursa con un periodo de excitación más prolongado, en comparación con el uso de la combinación xilazina-ketamina. Esto último se debe a la larga acción del zolacepam (relajación muscular), que se traduce en ataxia. ${ }^{81}$

\section{Propofol}

$\mathrm{Al}$ administrarlo como único agente anestésico, se llega a observar inducción difícil con movimientos ocasionales e impredecibles de las extremidades, taquicardia y depresión respiratoria. ${ }^{83}$ Únicamente se recomienda en potros. ${ }^{84}$

\section{Anestésicos halogenados}

Aun cuando se cuente con protecciones adecuadas en el quirófano, las altas concentraciones de halotano predisponen la presentación de miositis posanestésica. ${ }^{85} \mathrm{Al}$ utilizar halotano (1.5 veces la concentración alveolar mínima) durante cuatro horas se observaron claudicaciones posanestésicas. Se concluyó que los cambios en la resistencia periférica son de extrema importancia en la producción de lesiones isquémicas tisulares. ${ }^{86}$ Cuando se mantuvo la anestesia con halotano (1.2 veces la concentración alveolar mínima) durante 12 horas hubo alteraciones de la función hepática y reducción del funcionamiento renal asociados a la anes- 
tesia. ${ }^{87}$ Cuando se premedicó acepromacina, se indujo la anestesia con midazolamketamina y se mantuvo con halotano a una concentración de $1.2 \%$ en ponis, se observó hipotermia, hiperoxia, acidosis respiratoria, hipotensión moderada e incremento ligero en las concentraciones de cortisol y lactato. ${ }^{88}$

Con isofluorano se detectó hipertermia en una potranca que tenía como diagnóstico de base, parálisis periódica por hiperkalemia. ${ }^{89}$ También se han presentado problemas de hipoxemia en caballos con cólico, a los que se les indujo a la anestesia con xilazinagliceril guayacol éter y ketamina, o tiobarbitúricos, mantenidos con isofluorano o halotano..$^{90}$

\section{Antibacterianos}

\section{Sulfonamidas}

Se ha observado que las sulfonamidas, en general, pueden ocasionar cristaluria, hematuria y obstrucción tubular renal, si el consumo de agua es bajo y el pH de la orina es ácido. ${ }^{91,92}$ Puede haber necrosis tubular renal por precipitación (debida a la concentración y solubilidad de la sulfa y al pH de la orina) y deposición de cristales ${ }^{93,94}$ Empero, la sulfamerazina, la sulfametazina y la sulfadiazina son muy solubles, por lo que, a pesar de su rápida excreción, precipitan poco. Sin embargo, el uso de bicarbonato de sodio (alcaliniza) y la terapia de fluidos (induce diuresis) reducen el efecto de precipitación de la sulfa disuelta y aumenta su eliminación, ${ }^{93}$ por lo que son raros los efectos tóxicos agudos y, si acaso, están asociados principalmente con hipersensibilidad, sobredosis o administración IV rápida. ${ }^{95}$

Se ha comentado que no deben usarse sulfonamidas con trimetroprim (STMP) en caballos con daño del parénquima hepático, alteraciones sanguíneas, enfermedad renal, urolitiasis o historia de sensibilidad a las sulfonamidas. ${ }^{96}$ Existe una gran discrepancia con los efectos adversos que produce la administración IV de STMP. Se han informado casos de presencia de prurito con la administración de sulfadiazina/trimetroprim (SDZ/TMP), ${ }^{97}$ ataxia durante algunos minutos con la administración de SDZ, ${ }^{93}$ excitación y fasciculaciones musculares con sulfadiametoxina/ormetroprim (SDM/OMP), ${ }^{98}$ alteraciones cardiorrespiratorias con SDM y sulfadimidina, ${ }^{99}$ aunque igualmente existen informes en los que no hay efectos adversos. ${ }^{100}$ La causa exacta de estos efectos no se sabe con exactitud, pero se ha postulado que la sensibilización cardiaca (inducida por estrés) puede ser un factor precipitante. ${ }^{95}$ Para evitar la incidencia de RA, que parece ser cada vez mayor después de la administración IV de STMP, se recomienda aplicar la STMP de manera lenta en no menos de 1 minuto. ${ }^{95}$ Por otra parte, existe un informe en el cual la administración IV de TMP $5.5 \mathrm{mg} / \mathrm{kg}$ disuelto en ácido láctico acuoso $(50 \mathrm{mg} / \mathrm{mL})$ produjo la muerte de uno de seis caballos por choque anafiláctico agudo. 101

Existen informes que indican que la administración oral de SDZ/TMP (30 $\mathrm{mg} / \mathrm{kg}$ ) es inocua. ${ }^{100}$ Sin embargo, otros autores ${ }^{102}$ observaron que la administración oral de la misma combinación durante tres o más días, produjo heces suaves y diarrea en $7 \%$ de los caballos tratados $(n=200)$. Se ha mencionado que las 
sulfonamidas potenciadas se han asociado con disminución del apetito, diarrea y muerte por cambios en la microflora intestinal. ${ }^{93,102}$ Estos fármacos no se reconocen como agentes causantes de colitis, aunque estas mismas se han asociado ocasionalmente con colitis aguda. ${ }^{103,104}$ Perrin et al. ${ }^{105}$ sospecharon que la administración oral de ptalilsulfatiazol y sulfadimidina, ambos a dosis de $66-830 \mathrm{mg} /$ $\mathrm{kg}$ durante siete días, junto con fenilbutazona, neomicina (30-300 mg/kg durante siete días), penicilina G sódica (33 $000 \mathrm{UI} / \mathrm{kg}$ IV durante dos días) y penicilina G procaínica (12 $500 \mathrm{UI} / \mathrm{kg}$ im durante cinco días), pudo haber causado el desarrollo de colitis por Clostridium difficile.

Se ha informado la presencia de sangrado profuso después de un procedimiento quirúrgico en caballos tratados con STMP, que cesó después de 48 horas de descontinuado el tratamiento. En el escrito original no se detallan dosis, intervalo de dosificación, ni vía de administración. ${ }^{106}$

\section{$\beta$-lactámicos}

La penicilina G procaínica constituye el antibacteriano más utilizado en la clínica de equinos. ${ }^{107-109}$ Su toxicidad es baja y se ha informado que la administración de 30 millones de UI/día por vía im durante siete meses no produjo RA, únicamente una leve irritación muscular en los sitios de aplicación; ${ }^{110}$ Sumano et al. ${ }^{109}$ informaron lo anterior con dos diferentes esquemas de dosificación durante tres días. En Australia de 1972 a 1987 sólo se notificaron 42 casos de RA en caballos, asociadas con este medicamento. ${ }^{111}$ Sin embargo, en este país y en un periodo de tres meses durante 1993, alrededor del 15\% de los caballos que recibieron penicilina procaínica presentaron RA al fármaco. ${ }^{112}$ Las causas de toxicidad en esta especie al utilizar penicilina procaínica se deben a una reacción anafiláctica, ${ }^{111}$ intoxicación por la penicilina, ${ }^{113}$ pero sobretodo a la toxicidad de la procaína. ${ }^{109,111,114,115}$ Otras causas no idiopáticas son la aplicación de productos caducos o alergia al excipiente. ${ }^{107}$ Anteriormente se creía que la anafilaxia a la penicilina era el efecto adverso número uno que producían los ßlactámicos. ${ }^{116}$ Sin embargo, se ha visto que la toxicidad a la procaína puede ser la causa del $90 \%$ de las RA en el uso de la penicilina procaínica. ${ }^{107,111}$ Esto último se puede deber a que los caballos son aproximadamente 20 veces más susceptibles que los humanos a la toxicidad por procaína y que la estimulación del SNC por procaína ocurre a concentraciones séricas mucho menores. ${ }^{111}$ Tobin et al. ${ }^{117}$ informaron que la infusión IV de procaína $(2.5 \mathrm{mg} / \mathrm{kg})$ produjo excitación del SNC a los 30-40 segundos de haberla administrado. A pesar de lo anterior, en Australia, las presentaciones de penicilina procaínica para uso veterinario contienen una concentración de procaína de $20 \mathrm{mg} / \mathrm{mL}$, y la única de uso humano sólo $7.3 \mathrm{mg} / \mathrm{mL} .{ }^{107}$ Además, al calentar la penicilina procaínica a $50^{\circ} \mathrm{C}$ (temperatura que se puede alcanzar durante el verano en la guantera del coche) durante uno o siete días, la concentración de procaína soluble se incrementó significativamente, lo cual puede influir sobre los efectos farmacológicos y toxicológicos. ${ }^{107}$ La procaína se metaboliza en el plasma y cuando la velocidad de absorción supera a la velocidad de hidrolización por las esterasas del plasma ( $\mathrm{vg}$, tratamiento reciente con organofosforados), se presenta la toxicidad. ${ }^{107,109,118,119}$ Por lo anterior, es más frecuente que la administración de 
una dosis alta de penicilina G procaínica en un solo sitio de aplicación produzca toxicidad; en este sentido se recomienda la administración de la misma dosis en varias fracciones y en varios sitios de aplicación. Además, debido a la cinética de primer orden de la penicilina G, es más factible lograr mayor concentración sanguínea del fármaco con el último esquema de dosificación en comparación con el primero. ${ }^{109}$

En caballos, la anemia hemolítica inmunomediada puede ser idiopática o inducida por enfermedades infecciosas, neoplasias hemolinfáticas ${ }^{120}$ o por la aplicación de penicilina procaínica. ${ }^{120-122}$ Esta última se da por una producción patológica de anticuerpos IgG, los cuales se unen a la penicilina que a su vez se fija de manera covalente a las proteínas de los eritrocitos y a las proteínas plasmáticas, este complejo (penicilina-proteína) se une a las membranas de los eritrocitos a los cuales también destruye, en este proceso intervienen macrófagos y la activación del complemento. ${ }^{120,121}$ Se observa bilirrubinemia, hipokalemia, anemia, trombocitopenia, leucocitosis, bilirrubinuria, urobilinogenuria, acidosis metabólica compensada parcialmente y prueba de Coombs positiva. ${ }^{120-122}$ Aunque la anemia hemolítica inmunomediada no es muy frecuente en caballos, si no se reconoce y no se trata oportuna y adecuadamente, puede ser fatal. ${ }^{121}$ Es posible detectar concentraciones plasmáticas de penicilina procaínica aun después de tres a cuatro días de haber administrado la última dosis, y aunque no son concentraciones terapéuticas, pueden contribuir a continuar el proceso hemolítico inmunomediado en un caballo sensibilizado. ${ }^{122}$ Sin embargo, la cantidad de penicilina adsorbida por la membrana de los eritrocitos, la concentración plasmática de la penicilina procaínica y la capacidad del anticuerpo determinan la severidad de la hemólisis. ${ }^{121}$

Se ha informado que la penicilina G sódica (Pen G Na) ocasiona alteraciones cardiopulmonares en caballos conscientes y anestesiados. ${ }^{99,123}$ Aunque este fármaco no se reconoce como agente causante de colitis, ocasionalmente se le ha asociado con colitis aguda cuando se administran altas dosis (30 000-50 000 UI/ $\mathrm{kg}$ ) del mismo. ${ }^{103,104}$

La ampicilina puede inducir enterocolitis letal. ${ }^{93} \mathrm{La}$ administración de pivampicilina oral $(25 \mathrm{mg} / \mathrm{kg}$ dos veces al día (bid) durante tres o más días resultó en la excreción de heces suaves y diarrea únicamente en 3\% de los caballos tratados $(n=200)$. Aparentemente, en los caballos en los que se reduce el apetito debido a la administración de pivampicilina, hay mayor predisposición a presentar diarrea. ${ }^{124}$

La cefaloridina es altamente nefrotóxica, ya que se acumula entre las células de los túbulos proximales, ocasionando necrosis tubular, ${ }^{94}$ por lo que no es recomendable usarla. La ceftriaxona $(60 \mathrm{mg} / \mathrm{mL})$ administrada a dosis de $14 \mathrm{mg} /$ kg por infusión IV en un periodo de cuatro minutos, produjo depresión, anorexia y signos de cólico moderado. No se recomienda el uso de esta dosis, ya que por la rápida eliminación que sufre en el caballo, es necesaria una administración frecuente, lo cual incrementa considerablemente los costos de la terapia. ${ }^{125} \mathrm{La}$ administración im de cinco dosis de ceftiofur ( $2 \mathrm{mg} / \mathrm{kg}$ bid) no ocasionó efectos adversos. ${ }^{126}$ Sin embargo, al administrarlo por vía im para tratar una infección 
de tracto respiratorio alto, ocasionó urticaria en cara y pecho, además de disnea moderada durante 40 horas. Se administró conjuntamente con sulfadoxina/TMP y fenilbutazona. ${ }^{27} \mathrm{La}$ aplicación en los músculos glúteos o semitendinosos de cuatro dosis de cefoxitina ( $20 \mathrm{mg} / \mathrm{kg}$ tres veces al día [tid]), ocasionaron, en una de cuatro yeguas, depresión, fiebre moderada $\left(38.3^{\circ} \mathrm{C}\right)$, disminución del apetito, claudicación del miembro posterior derecho (MPD), edema en los músculos semitendinosos y en la región perianal; la claudicación del MPD empeoró y posteriormente, también se observó en el MPI; al examen físico se diagnosticó laminitis aguda, la cual se corroboró en la necropsia. ${ }^{127}$

\section{Tetraciclinas}

Las tetraciclinas decoloran la dentina durante el desarrollo de los dientes en el periodo de gestación o durante la muda dentaria. ${ }^{128,129}$ Ocasionan diarreas severas y colitis fatal, posiblemente por el cambio de la microflora en el ciego y colon. ${ }^{129-132}$ La administración IV rápida de preparados farmacéuticos a base de propilenglicol y 2-pirrolidona producen efectos cardiovasculares adversos como alteraciones electrocardiográficas (ECG), hipotensión y colapso. ${ }^{93,133}$ Se pueden desarrollar superinfecciones; ${ }^{129}$ como en el caso de un portador de Salmonella, el cual desarrolla diarrea posestrés exacerbada por la terapia con tetraciclinas, dado que éstas remueven las bacterias antagonistas de la microflora normal contra Salmonella y, generalmente, esta última es resistente a las tetraciclinas. ${ }^{104}$ Algunas condiciones preexistentes como la hipovolemia, hipoxemia, toxemia, hemoglobinuria, mioglobinuria, hiperbilirrubinemia, septicemia o el uso concurrente de fármacos nefrotóxicos potencializan el efecto tóxico de las tetraciclinas. ${ }^{134}$ Éstas pueden ser hepatotóxicas debido a su acumulación si es que existe una eliminación renal ineficiente o por la administración frecuente de dosis más altas de las recomendadas. ${ }^{129}$ También pueden ocasionar necrosis tubular renal (se incrementa en casos de endotoxemia) y degeneración grasa del hígado (se incrementa en casos de preñez). ${ }^{93}$

En particular, la doxiciclina por vía oral ocasiona irritación gastrointestinal y superinfecciones en duodeno e intestino grueso; por vía im produce irritación en el sitio de aplicación. ${ }^{135} \mathrm{Al}$ administrarla en caballos y ponis por infusión IV a dosis que van de 0.18 a $10 \mathrm{mg} / \mathrm{kg}$ y en un tiempo de infusión variable (3-40 minutos), se observó depresión, agitación, ansiedad, fasciculaciones musculares, taquicardia, taquipnea, disnea, arritmias, alteraciones ECG, colapso, paro cardiaco y en ocasiones muerte. Algunos caballos se recuperaron y otros fueron sacrificados. Estos eventos se relacionan con la velocidad de administración y no con la dosis administrada. ${ }^{135,136}$ La administración parenteral de doxiciclina en equinos no se recomienda. ${ }^{96}$ La oxitetraciclina aplicada por vía IV a dosis de $15 \mathrm{~g}$ durante 4-12 días ocasionó la muerte por colitis hemorrágica aguda en cinco de siete caballos. ${ }^{137}$ En ponis y caballos bajo estrés, la aplicación de tan solo 1-2 mg/ $\mathrm{kg}$ de oxitetraciclina produjo diarrea y colitis fatal, que posiblemente se debió a cambios en la microflora del ciego y colon..$^{103,130,131,138}$ En un neonato de un día de edad con isoeritrolisis neonatal, la administración de $70 \mathrm{mg} / \mathrm{kg}$ IV de oxitetraciclina para tratar la contractura del tendón flexor, ocasionó hematuria, letargo, 
edema en las articulaciones metacarpo y metatarsofalángicas, edema y alteraciones del patrón bronquial, azotemia, hiponatremia, excreción fraccional de sodio alta, anemia, proteinuria, glucosuria, hemoglobinuria, consistentes con un patrón de falla renal aguda. ${ }^{134}$

\section{Aminoglicósidos}

La nefrotoxicidad es un efecto colateral bien identificado con el uso de aminoglicósidos. Probablemente hay efectos nefrotóxicos subclínicos en todos los pacientes que reciben cualquiera de estos fármacos; sin embargo, la nefrotoxicidad clínica se presenta con $\mathrm{m}$ ayor frecuencia en pacientes geriátricos o pediátricos, o cuando hay disminución del volumen circulante, existencia de disfunción renal o hepática, sepsis, alteraciones electrolíticas o exposición a otros fármacos nefrotóxicos ( $v g$, antiinflamatorios no esteroidales) o nefroactivos ( $v g$, diuréticos). ${ }^{93,139,140}$ Es común que al menos alguno de estos factores se presente con regularidad en caballos con problemas clínicos. ${ }^{139,140}$ No se conoce con exactitud el mecanismo por el cual se produce la nefrotoxicidad. ${ }^{140}$ Se ha correlacionado el riesgo de nefrotoxicidad con la acumulación de aminoglicósidos en la corteza renal durante el pico de concentración del fármaco, con la duración del tratamiento y con el intervalo de administración; ${ }^{41}$ sin embargo, toxicológicamente, la cantidad de fármaco administrado y su concentración plasmática durante los intervalos de dosificación son más importantes que el pico de concentración del fármaco. Se puede reajustar la dosis para cada caso por medio de seguimiento farmacológico. ${ }^{93}$ También el agente específico juega un papel importante en la presentación de efectos nefrotóxicos ( $\mathrm{g}$, la neomicina es más tóxica que la estreptomicina). ${ }^{93}$ Se sabe que afectan varias funciones de la nefrona, al principio hay daño y disfunción tubular seguida de disminución en la velocidad de filtración glomerular. Esto produce cambios físicos en la orina (proteinuria, hematuria, cilindruria y disminución en la capacidad de concentración) y en los parámetros sanguíneos (aumento en la concentración de urea y creatinina y cambios electrolíticos). ${ }^{139}$

La toxicidad de la gentamicina se ha asociado con concentraciones pico mayores de $12 \mu \mathrm{g} / \mathrm{mL}$ y mayores de $2 \mu \mathrm{g} / \mathrm{mL}$ al momento de administrar la siguiente dosis. ${ }^{142}$ Para prevenir o corregir efectos tóxicos por este fármaco, se ha correlacionado la concentración de creatinina plasmática con la depuración de la gentamicina en caballos clínicamente sanos y enfermos, lo cual permite hacer ajustes en la dosificación del fármaco. ${ }^{143} \mathrm{La}$ administración IV ( $8.8 \mathrm{mg} / \mathrm{kg} /$ día) durante 5-14 días indujo nefropatía tóxica demostrada por el incremento en la concentración de urea y creatinina. ${ }^{144}$ Además del incremento en la concentración de urea y creatinina, hubo hiposmolaridad de la orina en uno de tres caballos a los que se les administró la misma dosis que en el estudio anterior, y en uno de tres a los que se les administró la dosis de $17.6 \mathrm{mg} / \mathrm{kg} /$ día, ambos regímenes durante 14 días. ${ }^{145}$ En potros la administración de $4.4 \mathrm{mg} / \mathrm{kg} /$ día durante 14 días no reveló evidencia funcional de nefropatía tóxica; sin embargo, histopatologicamente se observó degeneración y necrosis tubulares compatibles con nefrosis tubular proximal. ${ }^{140}$ La administración de $20 \mathrm{mg} / \mathrm{kg}$ de gentamicina por vía IV tid durante 14 días en 
ponis, ocasionó nefrotoxicosis de grado variable. Dos ponis desarrollaron falla renal aguda y fueron sacrificados antes de concluir el tratamiento, otros cinco no mostraron anormalidades físicas o de comportamiento durante el tratamiento. Sin embargo, todos desarrollaron anormalidades ultraestructurales en el epitelio tubular proximal compatibles con nefrotoxicidad por gentamicina. ${ }^{146}$ Incluso la dieta influye en la nefrotoxicidad por aminoglicósidos; si se alimenta un equino sólo con avena entera (pobre en Ca y K) se favorece la nefrotoxicidad por gentamicina de manera más clara que con heno de alfalfa (rico en vitaminas y minerales). Esto último ha inducido a los investigadores a concluir que la dieta es importante en la nefrotoxicidad inducida por gentamicina. ${ }^{147}$ Los caballos anoréxicos o que consumen dietas bajas en minerales están más predispuestos a la nefrotoxicidad por gentamicina. ${ }^{140}$ En ponis clínicamente sanos no se logró inducir toxicidad a dosis de $5 \mathrm{mg} / \mathrm{kg}$ im tid durante 7-14 días. Sin embargo, los autores sugieren que se hubiera podido presentar si se tratara de animales enfermos, ya que éstos están más predispuestos a la toxicidad. ${ }^{142}$ Brumbaugh $^{93}$ menciona que se puede inducir enterocolitis letal con gentamicina; sin embargo, no hace referencia sobre la dosificación.

La administración im de neomicina (10 mg/kg bid) durante 10 días (21 dosis) en caballos clínicamente sanos, ocasionó induraciones y algo de dolor en los sitios de aplicación, así como daño tubular renal (enzimuria y cilindruria) a los cuatro días de tratamiento, el cual disminuyó después de concluido. No se detectó nefrotoxicidad funcional significativa. Sin em bargo, debe esperarse mayor nefrotoxicidad en caballos enfermos que reciban neomicina, por lo que es recomendable realizar un seguimiento estrecho mediante pruebas clinicopatológicas. ${ }^{139}$

\section{Macrólidos}

A la eritromicina se le ha asociado ocasionalmente con colitis aguda. ${ }^{103,104}$ Es bien sabido que la administración parenteral puede inducir diarrea severa, que generalmente no es fatal y se detiene con la suspensión del tratamiento. ${ }^{93,148}$ Brumbaugh ${ }^{93}$ menciona, por referencia a su casuística, que la eritromicina puede inducir enterocolitis letal.

\section{Lincosamidas}

No se recomienda el uso de lincomicina y clindamicina en equinos, ya que produce colitis aguda. ${ }^{16,93,104,128,132}$ La administración de lincomicina por vía oral a razón de $25 \mathrm{mg} / \mathrm{kg}$ bid durante cuatro, cinco o siete tratamientos induce una colitis severa casi siempre fatal. Los signos que se observan son diarrea, taquicardia, dolor abdominal, deshidratación progresiva, depresión y muerte. Los cambios macro y microscópicos fueron consistentes con colitis y tiflitis. ${ }^{132}$ No se ha determinado experimentalmente la dosis tóxica mínima por vía oral; sin embargo, se propone que $0.5 \mathrm{mg} / \mathrm{kg}$ por día durante dos días ocasiona signos clínicos que incluyen diarrea, taquicardia, membranas oscuras, fiebre $\left(40.3^{\circ} \mathrm{C}\right)$, sudoración, postración, laminitis, hemorragia, choque endotóxico y colitis necrótica seudomembranosa fatal. ${ }^{93,149}$ 


\section{Quinolonas}

Se sabe que las fluoroquinolonas producen daño en las articulaciones que soportan el peso del animal en desarrollo o inmaduro, ${ }^{148}$ por lo que no deben administrarse a animales jóvenes que aun se encuentran en fase de desarrollo óseo ( $v g$, caballos jóvenes y yeguas gestantes). ${ }^{150}$ La enrofloxacina ocasiona artropatía asociada con defectos cartilaginosos inducidos. Aun a la dosis más baja (5 mg/kg sid) utilizada en este estudio, hubo claudicación y aumento de volumen en articulaciones en uno de cuatro caballos adultos (3-11 años de edad) a partir del día 19 de tratamiento, de un total de 21 días. Concluido el tratamiento, a la necropsia, dos caballos mostraron lesiones medias en cartílago articular. Dosis mayores produjeron lesiones más temprano durante el tratamiento y fueron más severas. Los potros fueron más propensos a las artropatías y se presentaron los signos desde el día seis de tratamiento, todos presentaron lesiones a nivel de cartílago articular. Aunque no existen datos para poder correlacionar las concentraciones plasmáticas de la enrofloxacina con los efectos tóxicos, parece ser que el grado de artropatía depende de la dosis. ${ }^{151}$

\section{Otros antibacterianos}

A pesar de la gran variedad de efectos adversos atribuidos al cloranfenicol en el hombre y los animales domésticos, ${ }^{120,148}$ existen pocos informes en equinos. Se ha observado dolor en el sitio de aplicación (cuando es por vía im) y efectos adversos con formulaciones a base de propilenglicol. ${ }^{152}$ Cuando se administró cloranfenicol (12.5 mg/kg po sid) durante 40 días no se observaron anormalidades sistémicas. ${ }^{153}$ Probablemente esta aparente seguridad del fármaco en los equinos se deba a su rápida depuración y a lo difícil que es lograr altas concentraciones sanguíneas. Al administrarlo por infusión continua se observó que, al mantener niveles terapéuticos constantes de cloranfenicol en sangre, puede alterar la respuesta inmune a la infección. ${ }^{154}$

Brumbaugh ${ }^{93}$ menciona que la vancomicina puede inducir enterocolitis letal; sin embargo, no hace referencia sobre la dosificación. En un estudio retrospectivo de 200 casos a los que se les administró metronidazol, se observó que produjo disminución del apetito tan sólo en cuatro caballos y este efecto se resolvió cuando se descontinuó la administración del medicamento. 155

\section{Antiinflamatorios no esteroidales}

La incidencia de toxicidad por antiinflamatorios no esteroidales (AINE) no es muy elevada. Por ejemplo, en Francia se detectaron 90 casos de toxicidad por AINE en perros en un periodo de seis años, mientras que en caballos sólo se registraron 11 casos. ${ }^{156}$ Aun así, es conveniente que el veterinario especialista en equinos conozca los riesgos asociados con el uso de estos fármacos con el fin de tomar las medidas profilácticas o terapéuticas apropiadas. 
Se ha demostrado que algunos AINE tienen la capacidad de inhibir la síntesis de adhesinas y la actividad fagocítica de los macrófagos. Al parecer, la flunixina meglumina tiene menos efectos indeseables al respecto. Se ha demostrado que los polimorfonucleares obtenidos de exudados inflamatorios en reposo o estimulados con zimosan o acetato de forbol-miristato e incubados con diversos AINE, reducen la actividad fagocitaria. La inhibición máxima (para la síntesis de adhesinas y la actividad fagocítica de los macrófagos, respectivamente) fue de $64 \%$ y $36 \%$ para el ácido acetilsalicílico; $32 \%$ y $17 \%$ para la fenilbutazona; $15 \%$ y $31 \%$ para el sulfóxido de dimetilo; 32\% y 19\% para el ácido salicílico y 0\% y 17\% para el salicilato de sodio. ${ }^{157}$

Hay una gran variedad de RA debido a la distribución de enzimas capaces de formar eicosanoides y a sus muchas funciones fisiológicas, ${ }^{158}$ los efectos colaterales más comunes de los AINE se asocian con el tubo gastrointestinal (TGI), el sistema hematopoyético y el renal. En raras ocasiones se observa meningitis aséptica, depresión del SNC o hepatotoxicidad. ${ }^{159-161}$

Puede haber erosión y ulceración gastroduodenal por inhibición de la PGI2 (prostaglandina I2) y la PGE2 (prostaglandina E2) (que a su vez inhibe la secreción del ácido gástrico) y de otras prostaglandinas responsables de la estimulación de la secreción de moco y bicarbonato que mantienen una barrera entre el ácido y las células gástricas. La PGE2 es un vasodilatador que regula el flujo sanguíneo a la mucosa del tracto gastrointestinal (TGI), la isquemia y la hipoxia generadas por su bloqueo son las condiciones que predisponen a la ulceración y erosión con hemorragias y, en algunos casos, pérdida de proteínas, que conlleva al desarrollo de anemia e hipoproteinemia. ${ }^{18}$ En caballos y potros se ha encontrado ulceración de la mucosa oral por la administración oral de fenilbutazona disuelta en pasta de melasa, lo que indica que un mayor tiempo de contacto con el fármaco incrementa la formación de úlceras en la boca. ${ }^{162}$

Se ha establecido que la fenilbutazona a razón de $10 \mathrm{mg} / \mathrm{kg}$ po sid en ponis, de $10 \mathrm{mg} / \mathrm{kg}$ po bid en potros y de $8-30 \mathrm{mg} / \mathrm{kg}$ IV una vez al día (sid) en caballos adultos puede causar RA como malestar gástrico con sangrado y colitis. Algo similar, sucede con la flunixina meglumina a dosis de $1.1 \mathrm{mg} / \mathrm{kg}$ po bid o im sid en potros y a razón de $1.1 \mathrm{mg} / \mathrm{kg}$ tid en ponis. El ketoprofeno a dosis de $2.2 \mathrm{mg} / \mathrm{kg}$ IV tid en caballos mostró los mismos efectos. ${ }^{163} \mathrm{Al}$ comparar los efectos adversos de la fenilbutazona (4.4 mg/kg), la flunixina meglumina ( $1.1 \mathrm{mg} / \mathrm{kg}$ ) y el ketoprofeno $(2.2 \mathrm{mg} / \mathrm{kg})$ administrados por vía IV cada ocho horas durante 12 días, se demostró que la porción glandular del estómago fue el área del TGI más afectada por los tres fármacos. Además la fenilbutazona ocasionó edema y erosiones del intestino delgado, así como úlceras en colon mayor, conjuntamente con hipoproteinemia e hipoalbuminemia. ${ }^{84}$ En este sentido, se estimó que el potencial tóxico de estos tres AINE es mayor para la fenilbutazona, menor para la flunixina meglumina y mucho menor para el ketoprofeno. ${ }^{164}$ Por otro lado, la aplicación de dipirona en forma crónica durante un mes sólo indujo malestares del TGI poco específicos. ${ }^{165}$ Hunt et al. ${ }^{166}$ informaron que la administración conjunta de dosis elevadas de isopirina, fenilbutazona y dipirona, a una yegua con historia de dolor abdominal persistente, pero no severo, ocasionó hemorragia dentro de la cavidad 
peritoneal; sin embargo, es el único informe que menciona este hecho. En casos de intoxicación crónica se pueden presentar cólicos intermitentes con o sin diarrea y pérdida de peso. ${ }^{163}$

En la sangre y sistema hematopoyético, inhiben la reacción de las plaquetas mediante la cual se conglomeran al impedir la síntesis de tromboxano. También se ha asociado a algunos AINE, como la fenilbutazona, con alteraciones de la médula ósea. Puede haber anemia asociada a hemorragias en el TGI. ${ }^{163}$

Las anormalidades más comunes en la química sanguínea, debidas a toxicidad por AINE, son hipoproteinemia e hipoalbuminemia, que predisponen al equino a edema ventral. ${ }^{167} \mathrm{La}$ fenilbutazona $(4.4 \mathrm{mg} / \mathrm{kg}$ cada ocho horas) modificó la concentración sérica de proteínas de $7.2 \mathrm{~g} / \mathrm{dL}$ en el día 0 a 5.5 y $5.2 \mathrm{~g} / \mathrm{dL}$ en los días 8 y 13, respectivamente. Generalmente no se incrementan las concentraciones séricas del nitrógeno úrico sérico (NUS) y creatinina hasta que el curso de la enfermedad se vuelve irreversible. ${ }^{168}$ En humanos, en un porcentaje mínimo de individuos, se ha asociado a la dipirona y a la fenilbutazona con agranulocitosis, a menudo mortal. En equinos no se ha informado de este efecto, y de hecho, en un ensayo de administración crónica no se obtuvo efecto alguno sobre las cuentas hemáticas. ${ }^{169}$

La administración IV de algunos AINE ( $v g$, fenilbutazona) debe realizarse con mucho cuidado, ya que si se realiza de manera extravascular puede causar inflamación y abscesos severos que en algunos casos ocluyen permanentemente la vena yugular. ${ }^{170}$

Los AINE pueden causar nefropatías al inhibir la síntesis de prostaglandinas vasoprotectoras, las cuales regulan el flujo sanguíneo renal, la filtración glomerular, el transporte tubular de iones, la liberación de renina y el metabolismo del agua. ${ }^{170} \mathrm{Al}$ disminuir la capacidad renal para autorregular el flujo sanguíneo hay riesgo de ocasionar isquemia renal localizada. ${ }^{163}$ MacAllister et al. ${ }^{164}$ observaron que uno de cinco y tres de tres caballos desarrollaron necrosis de la cresta renal con la aplicación de flunixina meglumina $(1.1 \mathrm{mg} / \mathrm{kg})$ y fenilbutazona $(4.4 \mathrm{mg} / \mathrm{kg})$ administradas por vía IV cada ocho horas durante 12 días. Los pacientes pediátricos, los que tienen problemas cardiacos, renales o hepáticos, los hipovolémicos o los que están recibiendo fármacos nefrotóxicos ( $v g$, aminoglicósidos, anfotericina B) o nefroactivos (diuréticos), están más predispuestos a la nefropatía por AINE.

\section{Acetaminofeno}

El principal signo de toxicidad es la metahemoglobinemia y puede haber necrosis hepática centrolobular. El tratamiento incluye la administración de antioxidantes (vitamina C); la cimetidina puede reducir la formación de metabolitos tóxicos si se administra dentro de las 48 horas posteriores a la administración del acetaminofeno. ${ }^{159}$

\section{Ácido acetilsalicílico}

Con sobredosis puede haber depresión, hipertermia, desbalance electrolítico, convulsiones, coma y muerte. La toxicidad aguda se manifiesta por desbalance en el equilibrio ácido-básico, hiperventilación, alteraciones en la coagulación y 
hepatotoxicidad. ${ }^{159} \mathrm{El}$ aumento en el tiempo de protrombina puede potencializar la epistaxis en algunos caballos en entrenamiento, durante o después del ejercicio. $^{158,159}$

\section{Ácido meclofenámico}

La sobredosis produce anorexia, depresión, debilidad, pérdida de peso corporal, sangre oculta en heces y reducción en el hematócrito. ${ }^{159}$ En ponis ocasionó hipoproteinemia después de 10 días de administración a la dosis recomendada de $2.2 \mathrm{mg} / \mathrm{kg} /$ día. ${ }^{158,159,170}$ Aun durante varios meses, la administración crónica 2.2 $\mathrm{mg} / \mathrm{kg} /$ día no induce cambios en la reproducción de yeguas y garañones. ${ }^{158,159,170}$ En yeguas ponis en el $2 / 3$ de gestación $2.2 \mathrm{mg} / \mathrm{kg} /$ día por dos periodos de 10 días consecutivos, cada uno el tiempo de gestación fue ligeramente mayor que en el grupo testigo. ${ }^{164}$

\section{Fenilbutazona FBZ}

Su índice terapéutico es estrecho. En comparación con los caballos, los ponis son más sensibles a la toxicidad por este fármaco. ${ }^{171}$ La formulación, la vía de administración, el horario de alimentación, la raza y la edad son factores que influyen para que se presenten RA por FBZ. Algunas de éstas son hemorragias, hepato y nefropatías, fiebre, edema abdominal y facial. ${ }^{158}$ Los signos iniciales de toxicidad gastrointestinal incluyen inapetencia, depresión, diarrea, pérdida de peso ${ }^{167,172,173}$ y, a veces, cólico; ${ }^{172-174}$ posteriormente se pueden observar signos clásicos de choque hipovolémico por hemorragia gastrointestinal. La toxicidad puede ocurrir incluso semanas después de haber suspendido su administración. A dosis de $13.46 \mathrm{mg} / \mathrm{kg} /$ día IV ocasionó daño microvascular del TGI (pequeñas erosiones pilóricas multifocales) a partir de las 24 horas posadministración. ${ }^{175-177}$ Además se detectaron erosiones anulares en el duodeno y necrosis de la mucosa del colon a las 48 horas. ${ }^{49,177}$ Puede ocasionar colitis ulcerativa del colon dorsal derecho por adsorción del fármaco en el forraje..172,173,178 Puede haber flebitis necrosante en venas portales después de la administración oral y en venas yugulares después de la administración IV. ${ }^{159}$ En caballos, una dosis de 13.63 mg/ $\mathrm{kg} /$ día durante tres días, indujo degeneración y dilatación de la pared de venas de calibre menor, además de alteraciones hematológicas y en la química sanguínea. ${ }^{158}$ En ponis se ha visto aumento en el número de neutrófilos y disminución en el de linfocitos. En caballos tratados (3-10 g/día) al menos durante días se observó disminución en los valores de hemoglobina y en el conteo de eritrocitos y de leucocitos. ${ }^{174}$ A dosis de $10 \mathrm{mg} / \mathrm{kg} /$ día en forma crónica, hay edema en la pared ventral del tórax y abdomen, hipoproteinemia e hipoalbuminemia de larga duración (2-3 meses). ${ }^{167}$ La administración crónica a yeguas ocasionó muy pocos efectos sobre su capacidad reproductiva ${ }^{179}$ y en garañones no hubo cambios. ${ }^{180}$ Empero, grandes cantidades de FBZ atraviesan la barrera placentaria y penetran a circulación fetal. ${ }^{181}$ En yeguas en lactancia, la concentración de FBZ en leche no excede del $2 \%$ de la concentración plasmática y en los potros no se detectan concentraciones del fármaco o metabolitos en plasma. ${ }^{182,183}$ A razón de 4.4 mg/ kg de FBZ IV sid durante cinco días hubo disminución en la concentración de 
glucosa plasmática, pero no en la de insulina sérica. No hubo efecto sobre tolerancia a la glucosa, sobre la secreción de insulina o sobre el área bajo la curva de la proporción insulina/glucosa contra tiempo. ${ }^{184}$ Incrementa la reabsorción tubular de Na y CL, por lo que está contraindicada en pacientes con disfunción cardiaca, hepática o renal. En pacientes deshidratados puede causar necrosis de la cresta medular renal. ${ }^{170,185} \mathrm{Al}$ administrar cuatro veces la dosis diaria recomendada de FBZ cúprica (vía tópica) durante cinco días, se observó irritación leve en la piel y se absorbió muy poco (trazas). ${ }^{186}$ En ponis los efectos tóxicos se pueden prevenir tratándolos conjuntamente con PGE2 sintética por vía oral. ${ }^{187}$ La administración de ranitidina ( $2 \mathrm{mg} / \mathrm{kg}$ IV bid) o sucralfato ( $4 \mathrm{~g}$ po bid) en potros de tres a cuatro meses de edad brinda sólo una protección parcial. ${ }^{163,188}$

\section{Flunixina meglumina FM}

Su toxicidad es rara, no se han observado reacciones adversas después de 10 días de administración a la dosis terapéutica. ${ }^{163}$ Produjo ulceración gástrica en $80 \%$ de los casos a una dosis de $1.1 \mathrm{mg} / \mathrm{kg}$ IV cada ocho horas (lo recomendable es cada 24) por 12 días. ${ }^{163}$ En una yegua poni, a razón de $3 \mathrm{mg} / \mathrm{kg}$ IV bid durante cinco días (cinco veces la dosis recomendada), produjo anorexia, depresión, ulceración oral, gástrica y colónica, neutropenia, hipoproteinemia e hipoalbuminemia. ${ }^{158}$ Más aún, en otros estudios en los que se administró tres y cinco veces la dosis recomendada por vía IV durante 10 y 5 días consecutivos, respectivamente, no se observaron signos clínicos ni bioquímicos de toxicidad. Algo semejante sucedió al administrar tres veces la dosis recomendada por vía oral durante 15 días consecutivos y por vía im durante 10 días consecutivos.158 El flujo plasmático renal efectivo y el flujo sanguíneo renal efectivo no se modifican significativamente con la administración de FM (1.1 mg/kg IV). ${ }^{189}$ En potros, dosis de 2.2-6.6 mg/ $\mathrm{kg}$ durante cinco días indujeron diarrea (no dependiente de la dosis), no hubo cambios significativos en la química sanguínea, aunque a los neonatos que se les administró la dosis más alta tuvieron una ligera hipoproteinemia. El día seis los neonatos que recibieron la dosis más alta mostraron ulceraciones gastroduodenales y hemorragias petequiales en el ciego; sin embargo, los autores concluyeron que no hubo diferencias clínico-patológicas significativas entre los neonatos tratados con el AINE, en comparación con los tratados con solución salina fisiológica. ${ }^{190,191}$ En potros, la dosis terapéutica recomendada $(1.1 \mathrm{mg} / \mathrm{kg})$ durante 30 días produjo erosiones en la porción glandular del estómago, sin importar la vía de administración oral o im. Al administrarla por vía oral produjo úlceras en la boca. ${ }^{187}$ Cuando se administró por vía IV provocó hiperventilación, sudoración, hiperactividad y temblores musculares. Estos signos se observan cuando la administración es intra-arterial o cuando la dosis es muy elevada (no se hace mención sobre la dosis); el dueño fue quien administró el medicamento. ${ }^{27} \mathrm{La}$ FM ( $1.1 \mathrm{mg} / \mathrm{kg}$ im durante cinco días) en casos de inflamaciones agudas y crónicas, disminuyó la proteína sérica y la proporción albúmina:globulina, aumentó las enzimas alanino aminotransferasa, aspartato aminotransferasa y fosfatasa alcalina, siendo más evidente en la aspartato aminotransferasa y en los caballos con procesos inflamatorios severamente agudos. ${ }^{192}$ 


\section{Indometacina}

Su toxicidad es poco predecible, pero mayor que la de otros AINE. A dosis de 2.5 $\mathrm{mg} / \mathrm{kg}$ puede ser tolerada por caballos adultos, ${ }^{158}$ pero dosis de $0.5-1 \mathrm{mg} / \mathrm{kg}$ inducen alteraciones del SNC, incluyendo ataxia y convulsiones en ponis. Estos últimos efectos son transitorios y duran 5-10 minutos. ${ }^{16}$ La administración de $1.47 \mathrm{~g}$ causó disfunción del SNC, manifestada por somnolencia, ataxia de los miembros posteriores y paresia, estos signos desaparecieron después de 24 horas. Además los caballos desarrollaron leucopenia y neutropenia y presentaron rastros de sangre en heces. ${ }^{181}$ Una sola dosis de 3 a $9 \mathrm{mg} / \mathrm{kg} /$ día po produjo somnolencia, desorientación, paresia, neutropenia y sangre oculta en heces. ${ }^{159}$

\section{Ketoprofeno}

A razón de $2.2 \mathrm{mg} / \mathrm{kg}$ IV durante 1-5 días no produjo RA. ${ }^{193}$ Cuando se administró cinco veces la dosis recomendada, no hubo evidencia alguna de toxicidad gastrointestinal; es mucho menos irritante que el ácido acetilsalicílico. ${ }^{170}$ Sin embargo, se han detectado erosiones y úlceras en lengua y en las porciones glandular y no glandular del estómago, pero no se menciona el régimen de administración utilizado. ${ }^{159}$ Por vía im en la región del cuello y de los glúteos por 4-7 días, no produce calor ni erupciones en el sitio de inyección y tampoco inapetencia. ${ }^{194}$

\section{Suxibuzona}

A razón de $6 \mathrm{mg} / \mathrm{kg}$ IV y a una velocidad de $20 \mathrm{~mL} / \mathrm{min} 150 \mathrm{mg} / \mathrm{mL}$ ocasionó escalofríos, incoordinación, ataxia de miembros torácicos y pélvicos, disnea, recumbencia, falta de respuesta a estímulos y muerte. Cuando se administró en forma más lenta $10 \mathrm{~mL} / \mathrm{min}$, se observó ataxia, indiferencia y disnea transitorias. No se recomienda la administración Iv. ${ }^{195}$

\section{Antiparasitarios}

\section{lonóforos}

Se utilizan como coccidiostatos y promotores del crecimiento en pollos de engorda y bovinos; ${ }^{196-199}$ generalmente, la fuente de exposición a los caballos es por consumo de alimento para pollos o bovinos, esto se da por libre acceso al mismo o por contaminación accidental durante la preparación de la premezcla alimentaria. 198,200

Aunque el sabor amargo de la monensina actúa como factor intrínseco de seguridad al limitar su consumo en los caballos, éstos son sumamente susceptibles a la intoxicación por este antibiótico; ${ }^{201}$ la DL50 en esta especie es de 2-3 mg/kg. ${ }^{197,202}$ En burros, al administrar una dosis oral única de 3 y $5 \mathrm{mg} / \mathrm{kg}$ no se observó mortalidad; sin embargo, al incrementarla a $10 \mathrm{mg} / \mathrm{kg}$ sí la hubo. ${ }^{197}$ Los signos que se observan son depresión, anorexia, diarrea, tambaleo, recumbencia, letargo, pelo quebradizo e hirsuto, pulso débil e irregular, pulso yugular positivo, taquicardia, arritmias, membranas cianóticas, sonidos pulmonares anormales, edema ventral y en miembros, cólico severo, colapso, muerte súbita, 
o en 48 horas después de la aparición de los signos. ${ }^{197,198}$ Existe la posibilidad de que los efectos se presenten con retraso en forma de bajo rendimiento y hasta muerte durante el ejercicio, por lo que es conveniente detectar estos casos subclínicos antes de que se manifiesten clínicamente. ${ }^{203}$ Electrocardiográficamente, hay latidos ectópicos ventriculares, depresión del segmento S-T, fibrilación atrial y taquicardia atrial paroxística, ${ }^{197,203}$ cambios ECG compatibles con hipokalemia e hipovolemia. ${ }^{198}$ Clinicopatológicamente, hay incremento en la creatinino-cinasa y las isomerasas 1 y 2 de la lactato dehidrogenasa; a la necropsia se observa necrosis del miocardio ${ }^{197}$ y lesiones hepáticas y renales. ${ }^{201}$ Las yeguas gestantes que no abortan y que se recuperan paren alrededor de 3-4 semanas después de la fecha esperada, los potros son débiles y presentan baja viabilidad. ${ }^{197}$

En caballos, la DL50 de lasolacid es de $21.5 \mathrm{mg} / \mathrm{kg}^{197}$ y produce anorexia, inquietud, poliuria, disnea, ataxia progresiva, recumbencia, intentos fallidos por levantarse y muerte. ${ }^{198,199}$ Clinicopatológicamente se observa hipocalcemia, hipofosfatemia seguida de hiperfosfatemia y normofosfatemia, hipopotasemia, bilirrubinemia, aumento de la urea y ácido úrico e hiperglucemia. ${ }^{197}$ Dosis únicas de $47.5 \mathrm{mg} / \mathrm{kg}$ po en burros no causaron mortalidad, pero al incrementar la dosis ( $57.5 \mathrm{mg} / \mathrm{kg}$ po) sí la hubo. ${ }^{198}$

La narasina produce anorexia, inquietud, poliuria, disnea, sudoración, ataxia progresiva, recumbencia, intentos fallidos por levantarse y muerte. ${ }^{199}$ Mientras que la salinomocina produce signos clínicos indicativos de miocarditis y macroscópicamente se observa fibrosis del miocardio. ${ }^{74}$

\section{Ivermectinas}

Cuando se administran por vía IV ocasionan muerte súbita por reacción anafiláctica. Sin embargo, son seguras cuando se administran por vía oral en forma de pasta o se inyectan por vía im, aun en animales jóvenes. ${ }^{33}$ No se recomienda su administración en potros menores de cuatro meses de edad. ${ }^{152} \mathrm{Al}$ administrar 10.6 veces $(2111 \mu \mathrm{g} / \mathrm{kg})$ la dosis recomendada en un neonato de 16 horas de edad, se observó incoordinación, presión de la cabeza contra objetos, depresión, sonidos intestinales aumentados, diarrea e hipoproteinemia (por probable falla en la transferencia pasiva de inmunoglobulinas). El tratamiento fue sintomático y se restableció después de tres días. ${ }^{152}$ En caballos adultos no se observaron efectos adversos cuando se administró a razón de $1200 \mu \mathrm{g} / \mathrm{kg}$ po (seis veces la dosis recomendada); sin embargo, cuando se administró a $2000 \mu \mathrm{g} / \mathrm{kg}$ po (10 veces la dosis recomendada), 5 de 11 caballos desarrollaron ataxia, depresión y falla aparente de la visión. Cuando se administró por vía im y a razón de 12000 g/ $/ \mathrm{kg}(60$ veces la dosis recomendada) se observó depresión, midriasis, ataxia, depresión respiratoria y caída del belfo inferior en todos los casos. Dos de cuatro caballos que recibieron una dosis de $6000 \mu \mathrm{g} / \mathrm{kg}$ im (30 veces la dosis recomendada), y dos de ocho caballos a los que se les administró a razón de $3000 \mu \mathrm{g} / \mathrm{kg}$ (15 veces la dosis recomendada) mostraron midriasis, falta de respuesta pupilar a la luz y ceguera. ${ }^{204}$ 


\section{Otros antiparasitarios}

El triclorfón en ponis induce diarrea a dosis de $40 \mathrm{mg} / \mathrm{kg}$ vía sonda nasogástrica. ${ }^{205} \mathrm{Al}$ administrarlo conjuntamente con oxfendazol por vía oral ocasionó diarrea, cólico, irritación oral e impactación intestinal. ${ }^{27}$ En caballos a los que se les administró triclorfón dos días antes de la anestesia con tiopental sódico, gliceril guayacol éter y halotano, se presentó aumento de la presión arterial pulmonar y del atrio derecho, así como disminución de la resistencia vascular pulmonar. En contraparte, la misma secuencia pero bajo anestesia fija con xilazina-ketamina, no indujo los cambios referidos; sin embargo, el tiempo de recuperación fue mayor. ${ }^{205}$

El amitraz no debe utilizarse bajo ninguna circunstancia en equinos. ${ }^{206-211}$ Disminuye la motilidad intestinal y provoca alteraciones en intestino grueso, las cuales no responden a los tratamientos de rutina; la consecuencia final es la muerte o eutanasia del equino. ${ }^{206,211}$ Todos los signos de toxicidad por amitraz se deben a su acción sobre receptores $\alpha$-adrenérgicos, lo que ocasiona alteraciones en la coordinación de fibras musculares lisas y aumento en la absorción hidro-electrolítica a nivel de colon. ${ }^{209}$ Aunque se ha sugerido que el atipamezol (0.15 mg/kg IV), un $\alpha$-antagonista selectivo, puede disminuir los signos, su eficacia clínica es relativa. ${ }^{167}$ La xilazina y detomidina están contraindicadas, ya que pueden agravar el cuadro por ser $\alpha$-agonistas. Tampoco se recomienda la rifampicina. ${ }^{208} \mathrm{Al}$ utilizar localmente soluciones a una concentración del 0.025-0.1\% se observan signos de intoxicación a las 6-48 horas, dependiendo de la concentración. ${ }^{208}$ Los signos que se pueden observar incluyen anorexia, disminución del tránsito intestinal, constipación, meteorismo, cólico, somnolencia, postración, ataxia, bradicardia, arritmias (bloqueo atrioventricular (AV), mucosas congestionadas, alteración de la temperatura rectal (hipo o hipertermia, y normotermia), sudoración, postración, hiperglicemia, hemoconcentración, hiperalbuminemia, hiperproteinemia, acidosis metabólica, hiperkalemia y muerte. ${ }^{207,208,210}$ A la palpación rectal se percibe timpanismo del colon y deshidratación de la materia fecal. $207,210,211$ Se ha postulado que la carga parasitaria en intestino es de importancia en la toxicidad del amitraz. ${ }^{207,210}$

La administración subcutánea (sc) de $0.025 \mathrm{~mL} / \mathrm{kg}$ de un compuesto con quinapiramina usado para el tratamiento de tripanosomiasis, ocasionó salivación e inquietud transitorias. En una mula ocasionó hiperpirexia y muerte a las 12 horas. $^{212}$

\section{Corticoides}

Se les puede considerar como antianabólicos, gluconeogénicos y diabetogénicos, ya que disminuyen la utilización periférica de glucosa y aumentan el almacenamiento de glucógeno hepático. Los efectos catabólicos pueden ocasionar reducción de masa muscular, ósea, adelgazamiento de la piel, pérdida del pelo y balance de nitrógeno negativo. ${ }^{213}$ También se ha informado de inhibición del crecimiento en animales jóvenes, así como de la respuesta inmune y de la corteza adrenal. ${ }^{214}$ La respuesta inmune se puede ver afectada por disminución de la actividad fagocítica de macrófagos y neutrófilos. ${ }^{215}$ Aunque hay informes en los que la ad- 
ministración de glucocorticoides no ocasionan RA, ${ }^{216,217}$ resulta difícil eliminar completamente las RA a estos medicamentos. Se ha comentado que su toxicidad depende de la duración del tratamiento, así como de la potencia del glucocorticosteroide. ${ }^{189}$ Quizá la RA más obvia sea la insuficiencia adrenal inducida por una terapia prolongada con glucocorticoides. ${ }^{218-222}$

En algunos caballos experimentales, la administración de 12 mg de acetonida de triamcinolona seguida de 200 mg ocasionó a la tercera y cuarta semanas, después de dos semanas del último tratamiento, poliuria, depresión, pérdida de peso, neutrofilia, linfopenia, glucosuria y elevación de los niveles de glucosa y de las enzimas aspartato transaminasa (AST) y gamma glutamiltransferasa (GGT), así como de ácidos biliares, y se detectó una supresión adrenal completa. Seis días después se presentaron casos de laminitis. ${ }^{218}$ Sin embargo, cabe señalar que el hiperadrenocorticismo inducido por glucocorticoides exógenos es menos común que el hiperadrenocorticismo por adenoma o hiperplasia de la glándula pituitaria. ${ }^{221,222}$

La administración intraarticular de corticoides puede ocasionar respuestas inflamatorias, artritis séptica, metaplasia ósea o artropatías. ${ }^{223,224}$ La respuesta inflamatoria es aséptica y se da por la suspensión de microcristales de los ésteres corticoides, la incidencia es aproximadamente del $2 \%$ y varía dependiendo del tipo de preparación utilizada. ${ }^{225}$ La artritis séptica se puede presentar por contaminación articular al momento de la artrocéntesis o por deposición hematógena de la bacteria en una articulación con resistencia disminuida a la infección a causa del corticosteroide. ${ }^{224}$ Las metaplasias óseas se deben a la deposición de corticoides de larga duración en los tejidos blandos periarticulares; se desconoce la causa de este efecto, se sospecha que el vehículo de los corticoides de larga duración es el responsable de este hecho, ya que no se ha observado este fenómeno con corticoides de corta duración. ${ }^{215}$ Las artropatías por corticoides se presentan cuando ya hay una lesión en el cartílago articular o cuando no se da el descanso apropiado después de la terapia. Se caracterizan por una acelerada destrucción articular con signos de claudicación, aumento de tamaño de la articulación por distención capsular y crecimento de hueso nuevo osteofítico, reducción del rango de movimientos y crepitaciones. ${ }^{215}$ Los cambios se pueden presentar con una sola aplicación; por ejemplo, $125 \mathrm{mg}$ de acetato de metilpredisolona y pueden perdurar por más de 16 semanas. ${ }^{225,226}$

Puede haber disminución de la elasticidad del cartílago, del conteo de glicosaminoglicanos y ácido hialurónico con disminución de la viscosidad del líquido sinovial y degeneración progresiva del cartílago. ${ }^{227}$ A la necropsia se observa adelgazamiento de la membrana sinovial, presencia de placas en la membrana sinovial y apariencia rugosa del cartílago articular. ${ }^{215}$ Cuando se administran corticoides en una articulación que involucra una fractura, la lesión se exacerba más que en aquellos que no reciben corticoides. Es posible que esto último se deba a que los corticoides retardan el proceso de curación de la fractura y a que reducen la inflamación sinovial (mitigando el dolor y permitiendo mayor funcionalidad, con lo que empeora la osteoartrosis). ${ }^{227}$ 
En caballos con uveítis, la administración prolongada (meses a años) e intermitente o continua de corticoides por vía oftálmica puede ocasionar deposición de calcio en la membrana basal del epitelio corneal interparpebral, además de retardar la cicatrización y ocasionar infecciones severas en los sitios de la queratectomia. 228

\section{Antiarrítmicos cardiacos}

Se sabe que todo antiarrítmico debe usarse bajo seguimiento con electrocardiografía (ECG), especialmente si se aplica por vía IV. Esta es la mejor manera de evaluar las arritmias ${ }^{229}$ y la eficacia o toxicidad de estos fármacos. ${ }^{230,231}$

\section{Antiarrítmicos de clase I}

\section{Quinidina}

Tiene un índice terapéutico estrecho; debe procurarse cuidado especial para evitar un flutter (aleteo auricular arrítmico), que provocaría fibrilación ventricular, potencialmente fatal. ${ }^{232,233}$ Tampoco se le debe utilizar en casos de insuficiencia cardiaca congestiva (ICC). ${ }^{234}$ Para evitar la aceleración potencial de la frecuencia ventricular producida por la quinidina, generalmente se premedica al paciente con glicósidos digitálicos. ${ }^{2,170}$ Sin embargo, se debe tener cuidado cuando se combine con digoxina, ya que los niveles plasmáticos de ésta aumentan con la administración conjunta de quinidina ${ }^{170,235}$ y pueden inducir toxicidad.

Algunos efectos indeseables de la quinidina incluyen aumento de volumen de la mucosa nasal (puede obstruir el paso del aire), urticaria, laminitis, molestia gastrointestinal, colapso cardiovascular, bloqueo atrioventricular (AV), otras arritmias, o muerte súbita. 2,93,236,237 Induce prolongación de los intervalos PR, QRS y QT. 2,170,193,234,235 Las dosis orales que exceden los 40 g por día predisponen la presentación de efectos indeseables. ${ }^{231}$ Las concentraciones terapéuticas fluctúan entre 2.5 y $5 \mu \mathrm{g} / \mathrm{mL}$ y concentraciones mayores a $5 \mu \mathrm{g} / \mathrm{mL}$ son tóxicas. No se logra la conversión de fibrilación atrial a ritmo sinusal durante el periodo en que se presentan los efectos tóxicos de la quinidina o cuando la concentración plasmática es mayor a $5 \mu \mathrm{g} / \mathrm{mL} .{ }^{235}$ Puede inducir reacciones alérgicas y es un inhibidor del sistema microsomal, por lo que aumenta el efecto de muchos anestésicos y tranquilizantes. ${ }^{235}$ La quinidina está contraindicada en pacientes con bloqueo cardiaco completo, pues les induce paro cardiaco y muerte. ${ }^{235}$ De acuerdo con Brumbaugh, ${ }^{93}$ se pueden utilizar bicarbonato de sodio $(0.5-1 \mathrm{mEq} /$ kg IV) y fluidos poliiónicos, para revertir temporalmente los signos.

\section{Procainamida}

$\mathrm{Su}$ metabolito activo (N-acetilprocainamida) tiene una vida media más larga y se puede acumular después de dosis múltiples. ${ }^{238,239}$ En pacientes con ICC se elevan las concentraciones plasmáticas de la procainamida y de la $\mathrm{N}$-acetilprocainamida, o debido a una disminución en la excreción urinaria y a la hidrólisis sanguínea de la procainamina. ${ }^{238} \mathrm{Su}$ toxicidad se manifiesta por un alargamiento del intervalo QT mayor al 50\%. ${ }^{239}$ Además, se pueden presentar arritmias adicionales, bloqueo AV, bradicardia, taquicardia o hipotensión.,2,170 


\section{Lidocaína}

El nivel terapéutico fluctúa entre 1 y $5 \mu \mathrm{g} / \mathrm{mL}$ (incluyendo lidocaína y metabolitos). Por lo general, las concentraciones mayores a $8 \mu \mathrm{g} / \mathrm{mL}$ son tóxicas. Los signos clínicos de toxicidad incluyen fasciculaciones nerviosas que progresan a convulsiones $^{170,234,236}$ y que pueden mitigarse con diazepan a razón de 0.1-0.2 mg/ kg IV. ${ }^{234}$ Hay además hipotensión, efectos cronotrópico e inotrópico negativos, ensanchamiento del complejo QRS, bloqueo cardiaco y paradójicamente, arritmias ventriculares. ${ }^{96,239}$ Es muy importante que se verifique que la lidocaína no contenga epinefrina. Para administrar la lidocaína se aconseja utilizar solución salina o Ringer, pues otras soluciones poliiónicas son químicamente antagónicas.

\section{Fenitoína}

La fenitoína es químicamente muy inestable y no se debe aplicar junto con ninguna otra sustancia. No se recomienda la administración im ya que se cristaliza en los tejidos, los necrosa e impide una absorción adecuada. ${ }^{235}$

\section{Antiarrítmicos de clase II}

\section{Propranolol}

No se debe administrar en casos de bloqueo AV profundo o ICC, 2,235,236 las consecuencias son evidentemente fatales debido a la drástica disminución del inotropismo cardiaco. Puede favorecer el broncoespasmo en pacientes predispuestos y tiene un impacto definido sobre la presión arterial y el corazón, induciendo hipotensión, bradicardia y disminución del gasto cardiaco. ${ }^{2,170}$ Es recomendable disponer de teofilina $(5 \mathrm{mg} / \mathrm{kg} \text { po })^{240}$ o salbutamol $(8 \mu \mathrm{g} / \mathrm{kg} \mathrm{IV}){ }^{241}$ para contrarrestar un broncoespasmo y dobutamina $(1-5 \mu \mathrm{g} / \mathrm{kg} / \mathrm{min})^{234}$ o isoproterenol $(0.4 \mu \mathrm{g} / \mathrm{kg} / \mathrm{min} \text {. })^{96}$ en caso de colapso cardiovascular. Cuando se utilizan conjuntamente propranolol y digitálicos pueden producirse diversos grados de bloqueo cardiaco. ${ }^{170,231,242}$ En un caballo medicado con p ropranolol u otros bloqueadores $ß$-adrenérgicos, la aplicación de casi cualquier narcótico puede inducir un colapso cardiovascular potencialmente fatal. ${ }^{243}$

\section{Antiarrímicos de clase III}

\section{Bretilio}

Disminuye el tono adrenérgico y, por ende, se observa severa hipotensión. 3,50,235 La administración de bretilio está contraindicada en pacientes anestesiados con compuestos halogenados, ya que sensibilizan al corazón a los efectos arritmogénicos de las catecolaminas endógenas y pueden producir arritmias ventriculares de larga duración. ${ }^{170,237}$ Además, por sí solo puede inducir diarrea, congestión nasal, dolor abdominal, bradicardia o eritema cutáneo. ${ }^{170}$

\section{Antiarrítmicos de clase IV}

Bloqueadores de canales de calcio

Tienen efectos inotrópicos negativos, por lo que no deben administrarse a pacientes con ICC y debe vigilarse que no provoquen una caída drástica de la presión arterial. ${ }^{170,237}$ Tampoco deben ser coadministrados con bloqueadores $ß$ debido 
al efecto depresor que ambos producen sobre el corazón. ${ }^{237}$ También se puede presentar bradicardia sinusal y bloqueo cardiaco por depresión directa de la velocidad de disparo del nodo sinoatrial (SA) y de la conducción del nodo AV. ${ }^{170,235}$

\section{Glicósidos digitálicos}

La dosis diaria de mantenimiento, una vez digitalizado el paciente, es de 1/8 a 1/4 de la dosis de digitalización. ${ }^{242,244}$ Sin embargo, es recomendable el seguimiento con electrocardiograma (ECG) y por medio de la concentración plasmática del fármaco para hacer los ajustes necesarios. En un estudio en caballos y burros en los que se utilizó digoxina a la dosis recomendada para el tratamiento de FCC, se encontró que los valores del fármaco eran tóxicos e inadecuados en 17\% y $54 \%$ de los casos, respectivamente. ${ }^{245}$

La ouabaina es más tóxica que la digitoxina o la digoxina. ${ }^{2}$ Concentraciones plasmáticas de digoxina de $0.5-2 \mathrm{ng} / \mathrm{mL}$ no son tóxicas en caballos ${ }^{24.6}$ y no se deben exceder los $2.5 \mathrm{ng} / \mathrm{mL} .{ }^{237}$ La digoxina puede ocasionar depresión, anorexia, bradicardia, alteraciones en la conducción AV, alargamiento del intervalo QRS y aumento de la excitabilidad atrial y ventricular. ${ }^{93,146}$ Además se presenta isquemia cardiaca y reducción del gasto cardiaco debido a un aumento no productivo de la contractilidad cardiaca, que sólo induce un aumento del consumo de oxígeno y de la resistencia vascular periférica. ${ }^{93,246}$ También se ha observado depresión, pérdida del apetito o diarrea. ${ }^{146}$ La hipokalemia, hipoproteinemia, falla renal, deshidratación, o la interacción con quinidina o verapamilo pueden potencialmente incrementar la toxicidad de la digoxina. ${ }^{93}$ Cuando se combinan glicósidos digitálicos más quinidina para el tratamiento de ICC, primero se administra el glicósido digitálico o en su defecto se administran simultáneamente los dos fármacos, ${ }^{146}$ ya que se pueden presentar riesgos considerables si se administra primero la quinidina, pues éste es un inotrópico negativo. ${ }^{237}$ No deben utilizarse digitálicos en casos de bloqueos de segundo grado o bloqueo AV completo. ${ }^{146}$

\section{Discusión}

Dada la considerable variedad de fármacos que llegan a utilizarse en los caballos, así como la amplia gama de situaciones clínicas en las que éstos se aplican, las reacciones referidas pueden variar en intensidad, frecuencia e incluso forma. De tal suerte, el clínico deberá ponderar si una reacción determinada es debida o no al fármaco aplicado. Empero, el conocimiento en sí de que puede ocurrir una RA con el fármaco administrado, es de por sí una base necesaria para identificarla. A fin de presentar toda la información compilada, en el Cuadro $1^{247-274}$ se resumen algunas RA identificadas para otras familias farmacológicas no incluidas en el texto. La información vertida lleva la intención de ser completa incluyendo las reacciones menos comunes.

El ejercicio médico conlleva la premisa hipocrática de primum non nocere (lo primero es no dañar); por ello, esta revisión pretende estimular a los clínicos a distinguir las RA y documentarlas a fin de enriquecer el quehacer clínico. Adi- 
Cuadro 1. Reacciones adversas más comunes en los equinos por grupos farmacológicos

(no se incluyen las reacciones descritas en el texto)

\begin{tabular}{r|} 
Fármaco \\
\hline Clenbuterol
\end{tabular}

Dopexamina (agonista adrenérgico)

\begin{tabular}{l} 
Anfotericina B \\
Heparina \\
Warfarina \\
\hline
\end{tabular}

Antitoxina tetánica

Atropina

Glicosaminoglicanos Ácido hialurónico

\section{Dimetilsulfóxido (DMSO)}

Furosemida

Bicarbonato $\mathrm{Na}$

\section{Electrólitos:}

Electrólitos + dextrosa al $2.5 \%$

\section{Nefrotoxicidad}

Hipokalemia y acidosis metabólica

Dolor e irritación en el sitio de inyección

Trombocitopenia, hemorragia fatal

Anemia normocítica normocrómica

Hipoprotrombinemia

\section{Enfermedad hepática aguda idiopática}

Aumento de la frecuencia cardiaca, gasto cardiaco, resistencia vascular sistémica y pulmonar, así como disminución de la fuerza de contracción y de la presión media del atrio derecho

Disminución de la motilidad y de sonidos intestinales Favorece la pérdida de agua y electrólitos en las heces y favorece la presentación de cólico

\section{Aumento del desarrollo de sepsis en}

artritis séptica inducida

Claudicación, aumento de volumen e inflamación

Sinovitis aséptica crónica

Temblores musculares, heces suaves, cólico hipertensión, hemólisis, hemoglobinuria y daño muscular

Aumento de volumen celular medio, en la concentración de $\mathrm{K}$ de los eritrocitos y en la viscosidad de la sangre, alterando el flujo sanguíneo

Reduce la presión media del atrio derecho y de la arteria pulmonar

Hipotensión, retarda la fatiga muscular en ejercicio submáximo

\section{Hiperproteinemia}

Alcalosis con, hipocloremia, hipokalemia, hipocalcemia y flutter diafragmático

Hipokalemia e hipernatremia

Pirexia las 24 h después de su aplicación

\section{Observaciones}

Durante la fase temprana del tratamiento (7\% de los casos)

$\mu \mathrm{g} / \mathrm{kg} / \mathrm{min}$

Sólo en caballos conscientes, no se observó en caballos anestesiados con halotano ni aun a dosis de 20 $\mu \mathrm{g} / \mathrm{kg} / \mathrm{min}$

Dependiente de la dosis

Ocasional

En sobredosis

Reacción adversa más común

Se exacerba con la fenilbutazona, ácido acetilsalicílico, metronidazol, sulfametoxasol, TMP, heparina, esteroides anabólicos, D-tiroxina, y algunos antimicrobianos

Evitarse en yeguas próximas al parto

En ponis

Algunos de estos signos se han registrado con el uso oftálmico

Por vía intraarticular

Por no refrigerarlo

Por vía intraarticular

Después de 10 minutos de administrado (4 g/kg IV)

0.05, 051.5 y $3 \mathrm{mmol} /$ litro en SSF

horas antes del ejercicio (1mg/ kg IV) 


\begin{tabular}{|c|c|c|c|}
\hline Fármaco & Reacción adversa & Observaciones & Ref. \\
\hline Sales de manganeso & $\begin{array}{l}\text { Defecación de heces acuosas, manoteo, inquietud, } \\
\text { cólico, bradicardia y sudoración }\end{array}$ & $\begin{array}{l}2.5 \text { a } 5 \text { g } \mathrm{MnCl} 2 \text { en SSF } \\
\mathrm{ml} / \mathrm{min} \text {. } \\
\text { Se contrarrestó con butorfanol }\end{array}$ & 36,39 \\
\hline $\begin{array}{l}\text { Nandrolona } \\
\text { Undecilinato de } \\
\text { baldenona }\end{array}$ & $\begin{array}{l}\text { Alteraciones en el comportamiento sexual } \\
\text { “ } \\
\text { “ } \\
\text { Reducción del tamaño testicular, de la } \\
\text { espermatogénesis, del volumen y calidad del eyaculado } \\
\text { “ } \\
\text { En yeguas, afección de desarrollo ovárico, supresión } \\
\text { o retardo en la ovulación, alteración de capacidad } \\
\text { reproductiva } \\
\text { Alargamiento de clítoris } \\
\text { Reducción testicular y calidad del eyaculado } \\
\text { Laminitis insuficiencia renal }\end{array}$ & $\begin{array}{l}\text { Aun después de seis semanas de } \\
\text { descontinuado el tratamiento } \\
\text { En yeguas tratadas durante un año } \\
\text { El efecto puede durar hasta un } \\
\text { año después de descontinuado el } \\
\text { tratamiento } \\
\text { El estanazolol tuvo menos efectos } \\
\text { tóxicos que la boldenona }\end{array}$ & $\begin{array}{l}264 \\
264 \\
265 \\
266 \\
267 \\
268\end{array}$ \\
\hline Estanazolol & Muerte súbita (5 minutos) & $\begin{array}{l}\text { Al cambiar el sitio de aplicación } \\
\text { posiblemente en un vaso } \\
\text { sanguíneo }\end{array}$ & 27 \\
\hline Prostaglandina $\mathrm{F}_{2 \mathrm{a}}$ & Ausencia de estro & Por vía sc & 27 \\
\hline Teofilina & $\begin{array}{l}\text { Sudoración, temblores musculares y signos nerviosos } \\
\text { Taquicardia y taquipnea } \\
\text { Ligera inquietud. Durante el ejercicio, aumento de la } \\
\text { frecuencia cardiaca y acumulación de lactato } \\
\text { Disminución en su eliminación con la consiguiente } \\
\text { acumulación Niveles plasmáticos tóxicos }\end{array}$ & $\begin{array}{l}\text { Concentraciones mayores de } 15 \\
\mu \mathrm{g} / \mathrm{ml} \\
\mathrm{Al} \text { administrarla con eritromicina } \\
\text { Junto con fármacos que se unen } \\
\text { en alto porcentaje a proteínas } \\
\text { plasmáticas }\end{array}$ & $\begin{array}{c}240 \\
269 \\
93 \\
43 \\
93 \\
93\end{array}$ \\
\hline Vitamina A & Resorción ósea, deformidades y hasta fracturas & $\begin{array}{l}\text { Cuando se administró } 1000 \text { veces } \\
\text { más la dosis recomendada }\end{array}$ & 270 \\
\hline Vitamina B12 & Ataxia, ansiedad, recumbencia y muerte & $\begin{array}{l}\text { En un informe donde se } \\
\text { administró IV junto con otras } \\
\text { vitaminas y minerales y a una } \\
\text { dosis mayor a la recomendada }\end{array}$ & 27 \\
\hline Vitamina D & $\begin{array}{l}\text { Es mas tóxica D3 que D2 } \\
\text { Calcificación de tendones y ligamentos = claudicación } \\
\text { Calcificación cardiaca y de grandes vasos = murmullos } \\
\text { cardiacos Problemas renales. Aumento de niveles } \\
\text { sanguíneos de P y Ca característicos } \\
\text { Calcificación en pulmones TGI y musculos } \\
\text { intercostales }\end{array}$ & $\begin{array}{l}\text { El efecto es acumulativo } \\
\text { Rara vez }\end{array}$ & $\begin{array}{l}271 \\
272 \\
273 \\
272\end{array}$ \\
\hline $\begin{array}{l}\text { Vitamina K3 } \\
\text { (Menadiona) }\end{array}$ & $\begin{array}{l}\text { Necrosis tubular renal } \\
\text { Falla renal } \\
\text { Cólico renal, hematuria, azotemia y desbalance } \\
\text { electrolítico }\end{array}$ & $\begin{array}{l}\text { Vía parenteral } \\
\text { No dependiente de la dosis }\end{array}$ & $\begin{array}{l}93,94 \\
272 \\
274\end{array}$ \\
\hline
\end{tabular}


cionalmente, a fin de tomar medidas correctivas, se deberá distinguir entre una RA inducida por sobredosis, clasificada como reacción tipo "A" y una generada por el mecanismo de acción del medicamento o por su interacción con otro, conocida como reacción tipo "B". Desafortunadamente, aún no se tiene una red de información sobre RA, como la que se ha instrumentando en otras partes del mundo. Un ejemplo de los beneficios de un sistema de acopio de los informes de RA en equinos, se presenta en las Figuras 1-4, de las que se pueden derivar datos de utilidad clínica, como la identificación del grupo farmacológico más relacionado con RA fatales y reacciones anafilácticas, que en el caso citado fueron los antibacterianos. Se destaca la elevada incidencia de RA en el tercer y quinto año de vida, posiblemente relacionando la edad con el número de fármacos utilizados en caballos dedicados a competencias de velocidad. Curiosamente, las vacunas arrojaron el mayor número de reacciones locales, aunque ninguna de ellas fatales. ${ }^{274}$

Las pretensiones de este artículo incluyen, evidentemente, actualizar a los clínicos al tiempo en que se les estimula a establecer vínculos encaminados a generar un sistema de vigilancia permanente sobre RA, que permita no sólo identificar una reacción determinada bajo una situación clínica específica, sino ubicar el medicamento, incluyendo marca, con el fin de forzar la mejoría en los procesos de su fabricación y control de calidad. 


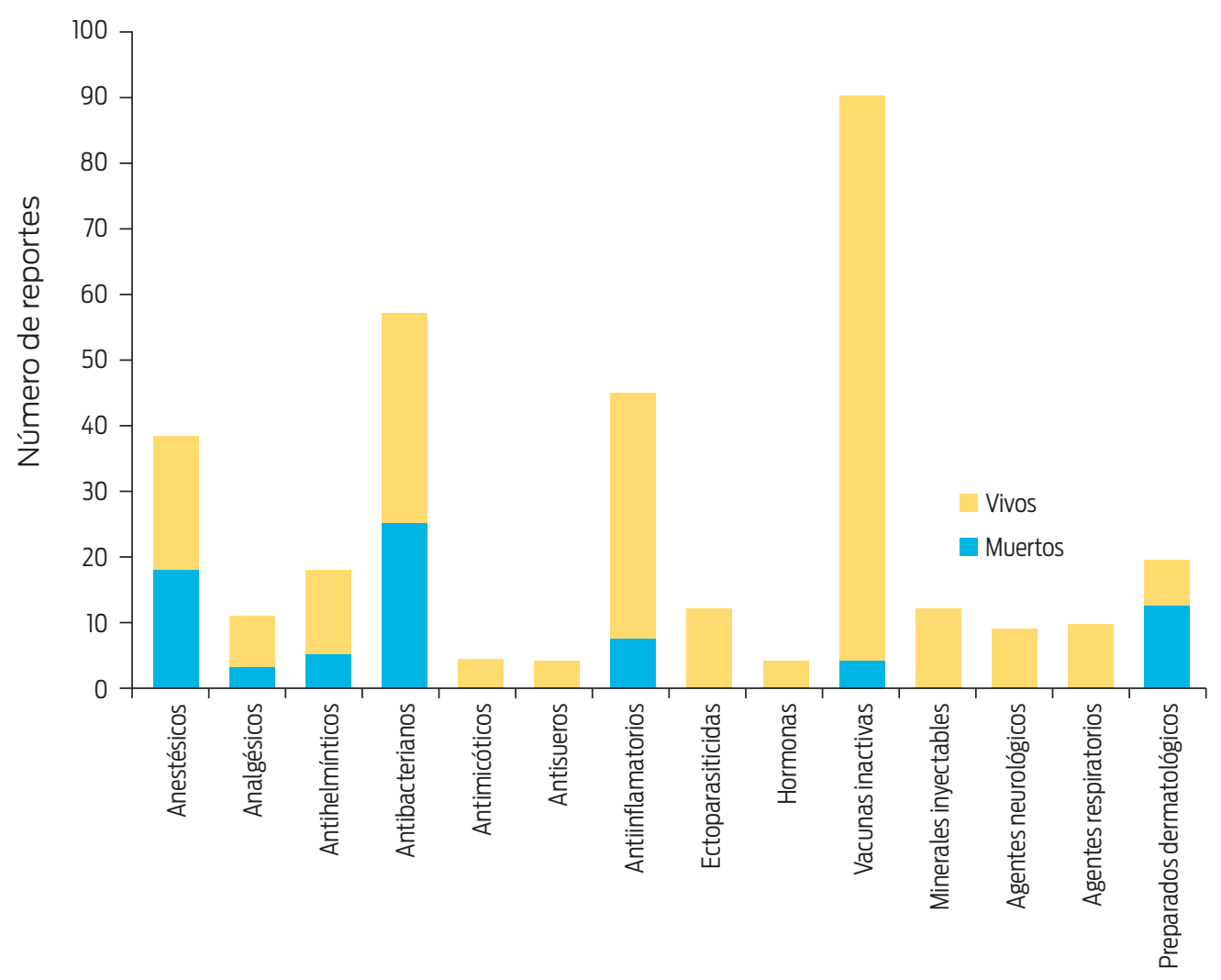

Grupos terapéuticos

Figura 1. Reacciones adversas por grupo terapéutico. (Adaptado de Gray [273]).

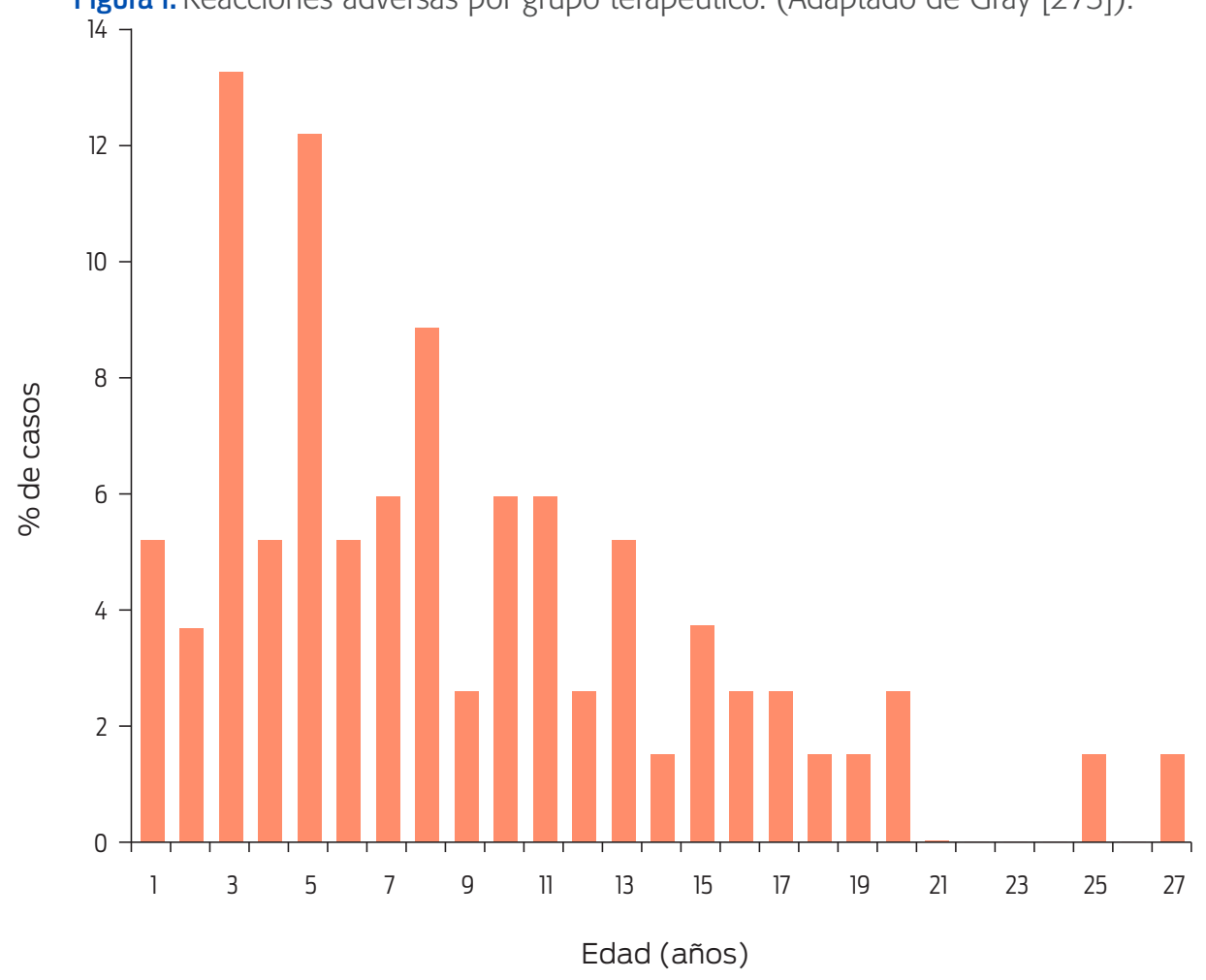

Figura 2. Distribución de reaccioneas adversas por edades (adaptado de Gray [275]). 


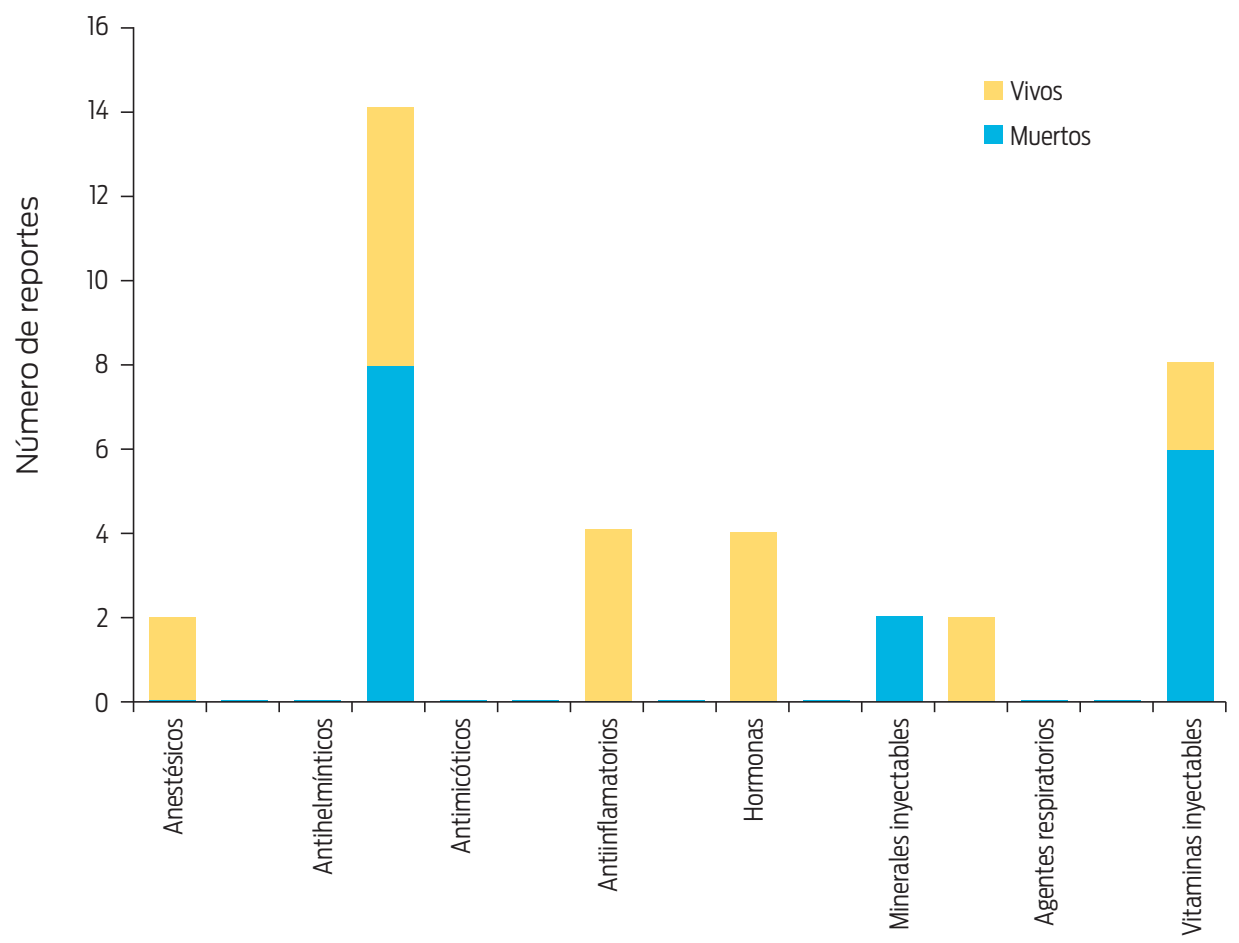

Grupos terapéuticos

Figura 3. Reacciones anafilácticas por grupo terapéutico. (Adaptado de Gray [273]).

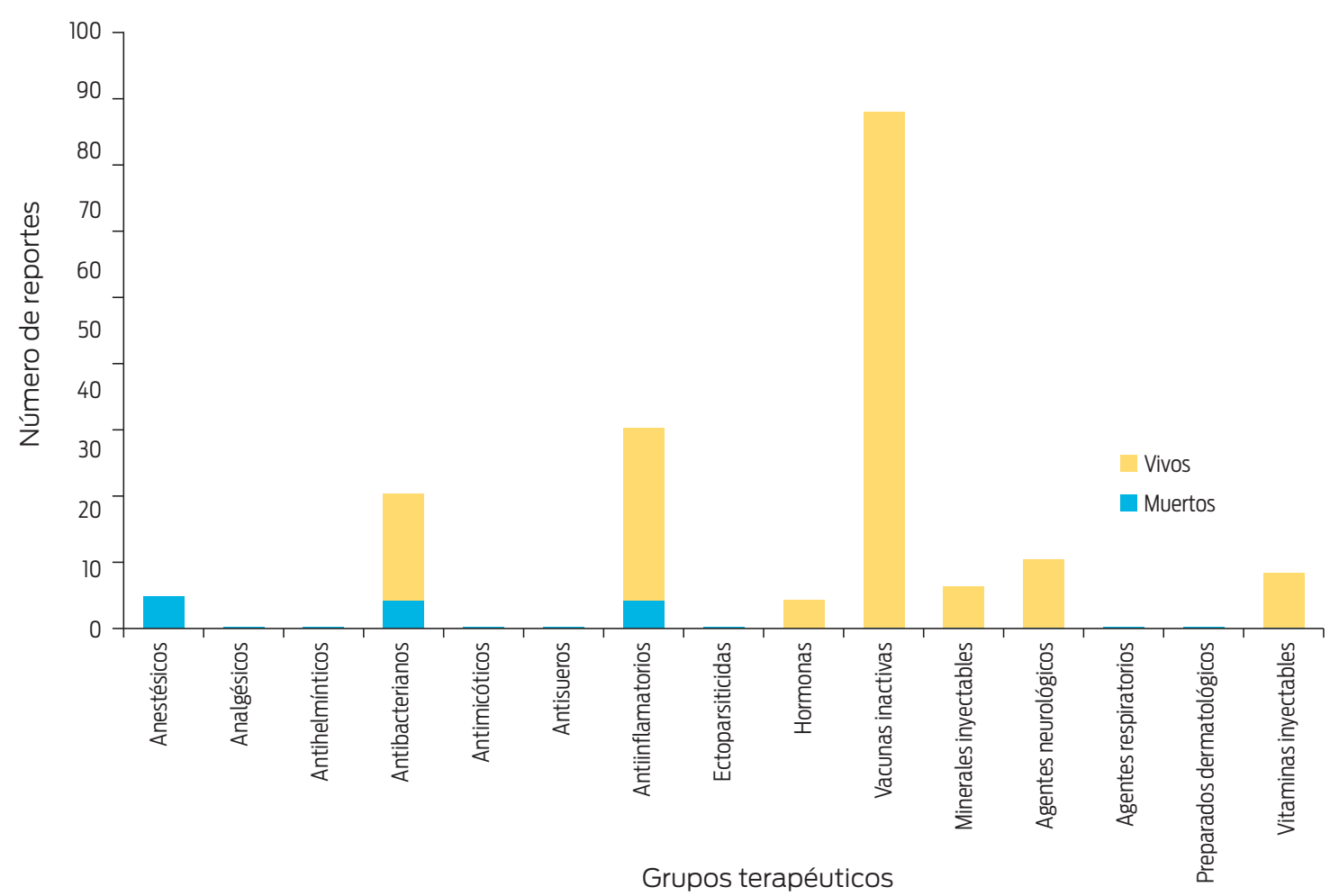

Figura 4. Reacciones locales en el sitio de administración. (Adaptado de Gray [273]) 


\section{Referencias}

1. Vomand CK, Sumano LH. Adverse drug reactions and interactions in bovine medicine. J Am Vet Med Assoc 1990;197:899-905.

2. Leblanc PH. Chemical restraint for surgery in the standing horse. Vet Clin North Am Equine Pract 1991;7:521523.

3. Sarazan RD, Strake WA, Krause GF. Cardiovascular effects of detomidine, a new 2-adrenoceptor agonist, in the conscious pony. J Vet Pharmacol Ther 1989;12:378-388.

4. Clarke KW, England GCW, Goossens L. Sedative and cardiovascular effects of romifidine, alone and in combination with butorphanol in the horse. J Vet Anaesth 1991;18:25-29.

5. Hubbell JAE, Muir WW. Emergency analgesia and chemical restraint in the horse. Vet Clin North Am Equine Pract 1994;10:503-516.

6. Muir WW. Standing chemical restraint in horses. In: Muir WW, Hubbell JAE, editors. Equine anesthesia. Monitoring and emergency therapy. St. Louis (Mo): Mosby Year Book, 1991:247-280.

7. Shaw ML, Carpenter JW, Leith DE. Complications with the use of carfentanil citrate and xylazine hydrochloride to immobilize domestic horses. J Am Vet Med Assoc 1995;206:833-836.

8. Short C, Maylin G, Collier M. Responses to submaximalexercise in Standardbred horses with and without medication. Equine Pract 1990;12:23-28.

9. Sumano LH, Fuentes VO. Efecto de la xilacina sobre larespuesta presora del perro anestesiado con pentobarbital. Vet Méx 1979;10:13-17.

10. Browning AP, Collins JA. Sedation of horses with romifidine and butorphanol. Vet Rec 1994;134:90-91.

11. Garner HE, Amend JF, Rosborough JP. Effects of Bay Va1470 on cardiovascular parameters in ponis. Vet Med Small Anim Clin 1971;66:1 016-1 021.

12. Gasthuys F, Parmentier D, Gossenes L, De Moor A. A preliminary study on the effects of atropine on bradycardia and heart blocks during romifidine sedation in the horse. Vet Res Comm 1990;14:489-502.

13. Kollias-Baker CA, Court MH, Williams LL. Influence ofyohimbine and tolazoline on the cardiovascular, respiratory, and sedative effects of xylazine in the horse. J Vet Pharmacol Ther 1993;16:350-358.

14. Leblanc PH, Caron JP. Clinical use of epidural xylazine in the horse. Equine Vet J 1990;22:180-181.

15. Short CE. Equine pain: use of non steroidal antiinflammatory drugs and analgesics for its prevention and control. Equine Pract 1995;17:12-22.

16. Vandenbossche GMR, Bouckaert S, De Muynck C, RemonJP, Mommens G, Van Zeveren A. Side effects of indomethacin in ponis. Vet Rec 1990;127:316.

17. Greene SA, Thurmon JC. Xylazine - a review of its pharmacology and use in veterinary medicine. J Vet Pharmacol Ther 1988;11:295-313.

18. Gasthuys F, Demoore A, Parmentier D. Haemodynamic changes during sedation in ponis. Vet Res Comm 1990;14:309-327. 
19. Hunt RJ, Brandon CI, Mccann M. Effects of acetylpromazine, xylazine, and vertical load on digital arterial blood flow in horses. Am J Vet Res 1994;55:375378.

20. Stashak TS. Lameness. Laminitis In: Stashak TS, editor.Adam's lameness in the horse. $4^{\text {th }}$ ed. Philadelphia: Lea \& Febiger, 1987;486-498.

21. Clarke KW, Paton BS. Combined use of detomidine with opiates in the horse. Equine Vet J 1988;20:331-334.

22. Stick JA, Chou CC, Dersen FJ. Effects of xylazine onequine intestinal vascular resistance, motility, compliance, and oxygen consumption. Am J Vet Res 1987;48:198-203.

23. Clark ES, Thompson SA, Becht JL, Moore JN. Effects of xylazine on cecal mechanical activity and cecal blood flow in healthy horses. Am J Vet Res 1988;49:720723.

24. Bertone JJ. Critical care in adult horses: restraint,analgesia, and anti-inflammatory support. Vet Med 1993;40:1 066-1 073.

25. Lavoie JP, Pascoe JR, Kurpershoek CJ. Effects ofxylazin on ventilation in horse. Am J Vet Res 1992;53:916-920.

26. Dyke TM. Sedatives, tranquilizers, and stimulants. Vet Clin North Am Equine Pract 1993;9:621-634.

27. Bureau of Veterinary Drugs. Suspected drug adversereactions reported to the Bureau of Veterinary Drugs. Can Vet J 1992;33:309-317.

28. Fuentes VO. Sudden death in a stallion after xylazine medication. Vet Rec 1979;102:106.

29. Taylor PM, Rest RJ, Duckham TN, Wood EJP. Possible potentiated sulphonamide and detomidine interactions. Vet Rec 1988;122:143.

30. Gleed RD. Tranquilizers and sedatives. In: Short CE,editor. Principles and practice in veterinary anesthesia. Baltimore (Md): Williams and Wilkins, 1987:17-27.

31. Thurmon JC, Steffy EP, Zinkl JG, Woliner M, Howland D. Xylazine causes transient dose-related hyperglycemia and increased urine volumes in mares. Am J Vet Res 1984;45:224-227.

32. Chopin JB, Wright JD. Complication after use of a combination of lignocaine and xylazine for epidural anaesthesia in a mare. Austr Vet J 1995;72:354-355.

33. Sumano H, Ocampo L. Farmacología veterinaria. México (DF): McGraw-Hill, 1988.

34. Raekalio M, Vaino O, Scheinin M. Detomidine reduces the plasma cathecholamines but not cortisol concentrations in horses. Zentralbl Veterinaermed 1991;38:153-156.

35. England GCW, Clarke KW, Goossenes L. A comparison of sedative effects of three -2 adrenoreceptor agonists (romifidine, detomidine and xylazine) in the horse. J Vet Pharmacol Ther 1992;15:194-201.

36. Bryant CE, England GC, Clarke KW. Comparison of thesedative effects of medetomidine and xylazine in horse. Vet Rec 1991;129:421-423. 
37. Willoughby RA, Ecker GL, Mckee SL Riddolls LJ. Use of scintigraphy for the determination of mucociliary clearence rates in normal, sedated, diseased and exercised horses. Can J Vet Res 1991;55:315-320.

38. Gasthuys F, Terpstra P, Van Den Hende C, De Moor A. Biochemical changes in blood and urine during halothane anaesthesia with detomidine premedication in the horse. J Vet Med 1988;35:655-664.

39. Thurmon JC, Neff-Davis C, Davis LE, Stoker RA, Benson CJ, Lock TF. Xylazine hydrochloride-induced hyperglycemia and hypoinsulinemia in thoroughbred horses. J Vet Pharmacol Ther 1982;5:241-245.

40. Henning GE, Court MH, King VL. The effect of xylazine on equine muscle surface capillary blood flow. J Vet Pharmacol Ther 1995;18:388-390.

41. Adams SB, Lamar CH, Masty J. Motility of the distal portion of the jejunum and pelvic flexure in ponis. Effects of six drugs. Am J Vet Res 1984;45:795-799.

42. Watson TD, Sullivan M. Effects of detomidine on equine oesophageal function as studied by contrast radiography. Vet Rec 1991;129:67-69.

43. Ingvast-Larsson C, Kallings P, Persson S, Appelgren LE, Wiese B. Pharmacokinetics and cardio-respiratory effects of oral theophylline in excercised horses. J Vet Pharmacol Ther 1989;12:189-199.

44. Gabel AA, Hamlin R, Smith CR. Effects of promazine and chloral hydrate on the cardiovascular system of the horse. Am J Vet Res 1964; 25:1151-1155.

45. Parry BW, Anderson GA, Gay CC. Hypotension in the horse induced by acepromazine maleate. Austr Vet J 1982;59:148-152.

46. Delbecke FT, Vynckier L, Debackere M. The disposition ofsuxibizone in the horse. J Vet Pharmacol Ther 1993;16:283-290.

47. Schatzmann U, Gerber H, Ianni O. Comparison of clinical repercussions between xylazine and propionylpromazine used as premedication for inhalation anaesthesia in the horse. Ippologia, 1995;6:63-68.

48. Hashem A, Keller H. Disposition, bioavailability and clinical efficacy of orally administrated acepromazine in the horse. J Vet Pharmacol Ther 1993;16:359-368.

49. Muir WW, Mason DE. Effects of diazepan, acepromazine, detomidine, and xylazine on thiamylal anesthesia in horses. J Am Vet Med Assoc 1993;203:1031-1038.

50. Ballard S, Shults T, Kownacki AA, Blake JW, Tobin T.The pharmacokinetics, pharmacological responses and behavioral effects of ecapromazine in the horse. J Vet Pharmacol Ther 1982;5:21-31.

51. Brewer BD, Hines MT, Stewart JT. Fluphenazine induced Parkinson-like syndrome in a horse. Equine Vet J 1990;22:136-141.

52. Kauffman VG, Soma L, Divers TJ, Perkons SZ. Extrapyramidal side effects caused by fluphenazine decanoate in a horse. J Am Vet Med Assoc 1989;195:1128-1130.

53. Kamerling SG. Narcotics and local anesthetics. Vet Clin North Am Equine Pract 1993;9:605-620.

54. Tobin T, Woods WE. Narcotics and stimulants: howthey affect horses. Proceedings of the Eleventh BainFallon Memorial Lectures; 1989 May 22-26; Co- 
ffs Harbour (Artarmon) Australia. Australia (New South Wales): Australian Equine Veterinary Asocciation, 1989:49-59.

55. Kamerling SG, Dequick DJ, Weckman TJ. Dose-relatedeffects of fentanyl autonomic and behavioral responses in performance horses. Gen Pharmacol 1985;16:253.

56. Mama KR, Pascoe PJ, Steffey EP. Evaluation of the interaction of mu and kappa opioid agonists on locomotor behavior in the horse. Can J Vet Res 1993;57:106-109.

57. Mcdonald J, Gall R, Widenbach P. Immunoassaydetection of drugs in horses. I. Particle concentration fluoroimmunoassay detection of fentanyl and its congeners. Res Comm Chem Pathol Pharmacol 1987;57:389-407.

58. Pascoe PJ, Black WE, Claxton JM, Sansom RE. Pharmacokinetics and locomotor activity of alfentanil in the horse. J Vet Pharmacol Ther 1991;14:317-325.

59. Pascoe PJ, Steffy EP, Black WD, Claxton JM, Jacobs JR,Woliner MJ. Evaluation of the effect of alfentanil on the minimum alveolar concentration of halothane in horses. Am J Vet Res 1993;54:1327-1332.

60. Plotka ED, Seal US, Eagle TC, Asa CS, Tester JR, Sniff DB. Rapid reversible immovilization of feral stallions using etorphine hydrochloride, xylazine hydrochloride, and atropine sulfate. J Wildlf Dis 1987;23:471-478.

61. Robertson SA. Metabolic and hormonal responses toneuroleptoanalgesia (etorfine and acepromazine) in the horse. Equine Vet J 1987;19:214-217.

62. Wilson DV, Nickels FA, Williams MA. Pharmacologic treatment of priapism in two horses. J Am Vet Med Assoc 1991;199:1 183-1 184.

63. Kamerling SG, Wood T, Dequick DJ, Weckman TJ, Tai C,Blake JW, Tobin T. Narcotic analgesics. Their detection, and pain measurement in the horse: a review. Equine Vet J 1989;21:4-12.

64. Gasthuys F, Vandamme R, De Moore A, Demeurichy W.Haemodynamic, metabolic, and physical responses to a neuroleptoanalgesic-glycerol guaiacolate combination in the horse. Vet Res Comm 1989;13:113-126.

65. Kamerling S, Wood T, DeQuick D, Weckman TJ, Tai C, Blake JW, et al. Narcotic analgesics, their detection and pain measurement in the horse: a review. Equine Vet J 1989;21:4-12.

66. Matthews NS, Lindsay SL. Effects of low-dose butorphanol on halothane minimum alveolar concentration in ponis. Equine Vet J 1990;22:325-327.

67. Nolan AM, Besley W, Reid J, Gray G. The effects of butorphanol on locomotor activity in ponis: a preliminary study. J Vet Pharmacol Ther 1994;17:323-326.

68. Kamerling SG, Dequick DJ, Weckman TJ. Dose-relatedeffects of ethylketazocine on nociception, behavior and autonomic responses in the horse. J Pharmacol 1986;38:40.

69. Kamerling SG, Weckman TJ, Donohoe J, Tobin T. Doserelated effects of the kappa agonist U50,488H on behaviour, nociception and autonomic response in the horse. Equine Vet J 1988;20:114-118.

70. Villar JI. Evaluación de los efectos cardiovasculares,hemáticos y anestésicos de la mezcla azaperonametomidato en equinos (tesis de licenciatura). México (DF) México: Facultad de Medicina Veterinaria y Zootecnia. UNAM, 1983. 
71. Dodman NH, Waterman E. Paradoxal excitement following the intravenous administration of azaperone in the horse. Equine Vet J 1979;11:33-35.

72. Muir WW, Sams RA, Huffman RH, Noonan JS.Pharmacodynamic and pharmacokinetic properties of diazepan in horses. Am J Vet Res 1982;43:1756-1762.

73. Norman WM, Dodman NH, Court MH. Interstitial $\mathrm{pH}$ and pressure in the dependent biceps femoris muscle of laterally recumbent anesthetized horses. Vet Surg 1988;17:234-239.

74. Nyman G, Funkquist B, Kvart C, Frostell C, Tokics L, Strandberg A, et al. Atelectasis causes gas exchange impairment in the anaesthetised horse. Equine Vet J 1990;22:317-324.

75. Trim CM. Anaesthesia and systemic disease: anoverview. J Vet Anaesth 1991;Special Suppl:29-34.

76. Hubbell JAE, Muir WW, Sams RA. Guafenesin: cardiopulmonary effects and plasma concentrations in horses. Am J Vet Res 1980;41:1751-1755.

77. Herschl MA, Trim CM, Mahaffey EA. Effects of 5\% and10\% guaifenesen on equine vascular endothelium. Vet Surg 1992;21:494-497.

78. Dickson LR, Badcode LM, Burbidge H, Kannegieter NJ. Jugular thrombophlebitis resulting from an anaesthetic induction technique in the horse. Equine Vet J 1990;22:177-179.

79. Matthews NS, Miller SM, Slater MR, Hartsfield SM, ShortCE. A comparison of xylazine-ketamine and detomidineketamine anaesthesia in horses. J Vet Anaesth 1993;20:68-72.

80. Mccarty JE, Trim CM, Ferguson D. Prolongation of anesthesia with xylazine, ketamine, and guaifenesin in horses: 64 horses (1986-1989). J Am Vet Med Assoc 1990;197:1646-1650.

81. Matthews NS, Hartsfield SM, Cornick JL, Williams JD, Beasley A. A comparison of injectable anesthetic combinations in horses. Vet Surg 1991;20:268-273.

82. Daunt DA. Detomidine in equine sedation and analgesia. Comp Cont Educ Pract Vet 1995;17:1 405-1 411.

83. Mama KR, Steffey EP, Pascoe PJ. Evaluation of propofol as a general anesthetic for horses. Vet Surg 1995;24:188-194.

84. Matthews NS, Chaffin MK, Erickson SE, Overhulse WA.Propofol anesthesia for non-surgical procedures of neonatal foals. Equine Pract 1995;17:15-20.

85. Lindsay WA, Robinson GM, Brunson DB, Majors LJ. Induction of equine postanesthetic myositis after halothane-induced hypotension. Am J Vet Res 1988;50:404-410.

86. Branson KR, Benson GJ, Thurmon JC, Olson WA, Tranquilli WJ, Dorner JL. Hemodynamic parameters and tissue oxygenation during halothane anesthesia in normal horses and those experiencing post anesthetic lameness. J Equine Vet Sci 1992;12:153-159.

87. Steffey EP, Giri SN, Dunlop CL, Cullen LK, Hodgson DS, Willits N. Biochemical and haematological changes following prolonged halothane anaesthesia in horses. Res Vet Sci 1993;55:338-345. 
88. Luna SPL, Taylor PM, Dick CJ. Midazolam andketamine induction before halothane anaesthesia in ponis. Cardiorespiratory, endocrine and metabolic changes. J Vet Anaesth 1993;20:49.

89. Cornick JL, Seahorn TL, Hartsfield SM. Hyperthermiaduring isofluorane anaesthesia in a horse suspected hyperkalemic periodic paralysis. Equine Vet J 1994;26:511514.

90. Trim CM, Wan PY. Hypoxaemia during anaesthesia inseven horses with colic. J Assoc Vet Anaesth GB 1990;17:45-49.

91. Wilson DA, MacFadden KE, Green EM, Crabill M,Frankeny RL, Thorne JG. Case control and historical cohort study of diarrhea associated with administration of trimetroprim-potentiated sulphonamides to horses and ponis. J Vet Int Med 1996;10:258-264.

92. Spoo JW, Riviere JE. Sulfonamides. In: Adams HR,editor. Veterinary pharmacology and therapeutics. $7^{\text {th }}$ ed. Ames (Io): Iowa State University Press, 1995a:753773.

93. Brumbaugh GW. Toxicity of pharmacological agents.In: Robinson EN, editor. Current therapy in equine medicine. $3^{\text {rd }}$ ed. Philadelphia: W.B. Saunders Co., 1992:353-358.

94. Schmitz DG. Toxic nephropathies. In: Robinson EN,editor. Current therapy in equine medicine. $2^{\text {nd }}$ ed. Philadelphia: W.B. Saunders Co., 1987:704-708.

95. Van Duijkeren E, Vulto AG, Van Miert A. Trimethoprim/sulfonamide combinations in the horse: a review. J Vet Pharmacol Ther 1994a:17:64-73.

96. Plumb DC. Veterinary drug handbook. $2^{\text {nd }}$ ed. Ames (Io): Iowa State University Press, 1995.

97. Miller EP, Gunderson GR, Collier MA. Clinical fieldevaluation of a sulfadiazine-trimethoprim combination in horses. Vet Med Small Anim Clin 1984;79:227-232.

98. Brown MP, Gronwall RR, Houston AE. Pharmacokinetics and body fluid and endometrial concentrations of ormetroprim-sulfadiamethoxine in mares. Can J Vet Res 1989;53:12-16.

99. Zeller W, Schatzmann U, Meier R, Tschudi P.Wirkungen von Na-penicillin G, Sulfadimidin, Sulfadimethoxin und Flunixin-Meglubin auf Atmung und Kreislauf nach intravenöser Applikation am anästhesierten Pferd. Schweiz Arch Thk 1988;130:329349.

100. Van Duijkeren E, Vulto AG, Sloet-Van OldruitenborghOosterbaan MM, Mevius DJ, Kessels

101. BGF, Breukink HJ, Van Miert A. A comparative studyof the pharmacokinetics of intravenous and oral trimethoprim/sulphadiazine formulations in the horse. J Vet Pharmacol Ther 1994;17:440-446.

102. Alexander F, Collett RA. Trimethoprim in the horse.Equine Vet J 1975;7:203-206.

103. Ensink JM, Klein WR, Barneveld A, Van Miert A, Vulto AG. Side effects of oral antimicrobial agents in the horse: a comparison of pivampicillin and trimethoprim/sulphadiazine. Vet Rec 1996;138:253256. 
104. Whitlock RH. Acute diarrhoeal diseases in the horse.Proceedings of the $21^{\text {st }}$ Annual Convention of the American Association of Equine Practitioners; 1975 Dec 1-3; Boston (Ma). Lexington (Ke): American Association of Equine Practitioners, 1976:309-401.

105. Whitlock RH. Colitis: differential diagnosis and treatment. Equine Vet J 1986;18:278-283.

106. Perrin J, Cosmetatos I, Gallusser A, Lobsiger L, Straub R, Nicolet J. Clostridium difficile associated with typhlocolitis in an adult horse. J Vet Diagn Invest 1993;5:99-101.

107. Dodds WJ. Sulfonamides and blood dyscrasias. J Am Vet Med Assoc 1990;196:681-682.

108. Chapman CB, Courage P, Nielsen IL Sitarman BR, Huntington PJ. The role of procaine in adverse reactions to procaine penicillin in horses. Austr Vet J 1992;69:129133.

109. Sullins KE, Messer NT, Nelson R. Serum concentration of penicillin in the horse after repeated intramuscular injections of procaine penicillin $\mathrm{G}$ alone or in combination with benzatine penicillin and/or phenylbutazone. Am J Vet Res 1984;45:1 003-1 007.

110. Sumano LH, Ocampo CL, López PG. Serum and synovial concentrations of penicillin $G$ in horses after two different dose schemes. Equine Pract 1994;16:18-21.

111. Miller RM. The case for penicillin. Vet Med 1971;66:300301.

112. Nielsen IL, Jacobs KA, Huntington PJ, Chapman CB, Pool R. Adverse reaction to procaine penicillin G in horses. Austr Vet J 1988;65:181-184.

113. Craddock S. Adverse penicillin reaction. Austr EquineVet 1993;11:157.

114. Tobin T. Pharmacology review: chemotherapy in thehorse- the penicillins. J Equine Med Surg 1978;2:475477.

115. Blucke G, Williams SW. Chemotherapy with antibiotics and allied drugs. $4^{\text {th }}$ ed. Canberra, Australia: Australian Goverment Publishing Service, 1978.

116. Kemble T. A procaine penicillin reaction in a 3-yearold Anglo Arab mare. Equine Vet Educ 1995;7:79-80.

117. English PB. Penicillin blood levels in the horse withfortified benzathine. Austr Vet J 1958;34:82-88.

118. Tobin T, Blake JW, Sturman L, Arnett S, Truelove J.Pharmacology of procaine in the horse: pharmacokinetics and behavioural effects. Am J Vet Res 1977;38:637-647.

119. Firth EC, Nouws JFM, Driessens F, Schmaetz P, Peperkamp K, Klein WR. Effect of the injection site on the pharmacokinetics of procain penicillin $G$ in horses. Am J Vet Res 1986;47:2380-2384.

120. Tobin T, Blake JW, Tai CY, Sturman L, Arnett S. Pharmacology of procaine in the horse: procaine esterase properties of equine plasma and synovial fluid. Am J Vet Res 1976;37:1165-1170.

121. Step DL, Blue JT, Dill SG. Penicillin induced hemolytic anemia and acute hepatic failure following treatment of tetanus in a horse. Cornell Vet 1991;81:13-18. 
122. Mcconnico RS, Roberts MC, Tompkins M. Penicillininduced immune-mediated hemolytic anemia in a horse. J Am Vet Med Assoc 1992;201:1402-1403.

123. Robbins RL, Wallace SS, Brunner CJ, Gardner TR, Difranco BJ, Speirs VC. Immune-mediated haemolytic disease after penicillin therapy in a horse. Equine Vet J 1993;25:462-465.

124. Hubbell JAE, Muir WW, Robertson JT, Sams RA.Cardiovascular effects of intravenous sodium penicillin, sodium cefalozin, and sodium citrate in awake and anesthetized horses. Vet Surg 1987;16:245250.

125. Freestone JF, Carlson GP, Harrold DR, Church G. Furosemide and sodium bicarbonate-induced alkalosis in the horse and response to oral $\mathrm{KCl}$ or $\mathrm{NaCl}$ therapy. Am J Vet Res 1989;50:1334-1339.

126. Gardner SY, Aucoin DP. Pharmacokinetics of ceftriaxone in mares. J Vet Pharmacol Ther 1994;17:155-156.

127. Cervantes CC, Brown MP, Gronwall R, Merritt K. Pharmacokinetics and concentrations of ceftiofur sodium in body fluids and endometrium after repeated intramuscular injections in mares. Am J Vet Res 1993;54:573-575.

128. Brown MP, Gronwall RR, Houston AE. Pharmacokinetics and body fluid and endometrial concentrations of cefoxitin in mares. Am J Vet Res 1986;47:1734-1738.

129. Brumbaugh GW, Langston VC. Principles of antimicrobial therapy. In: Smith BP, editor. Large animal internal medicine. St. Louis (Mo): The C.V. Mosby Co., 1990:1436-1451.

130. Riviere JE, Spoo JW. Tetracycline antibiotics. In: Adams HR, editor. Veterinary pharmacology and therapeutics. $7^{\text {th }}$ ed. Ames (Io): Iowa State University Press, 1995:784-796.

131. Fey K, Sasse HH. The impact of antibiotics on the fecal flora of the horse- a review. Pferdeheilkunde 1997;13:11-22.

132. Cook WR. Diarrhoea in the horse associated withstress and tetracyclin therapy. Vet Rec 1973;93:15-16.

133. Prescott JF, Staempfli HR, Barker IK, Bettoni R, DelaneyK. A method for reproducing fatal idiopathic colitis (colitis $\mathrm{X}$ ) in ponis and isolation of a Clostridium as a possible agent. Equine Vet J 1988;20:417-420.

134. Potter WC. Collapse following intravenous injection of oxytetracycline in two horses. Austr Vet J 1973;49:547548.

135. Vivrette S, Cowgill LD, Pascoe J, Suter C, Becker T. Hemodialysis for treatment of oxytetracyclineinduced acute renal failure in a neonatal foal. J Am Vet Med Assoc 1993;203:105-107.

136. Riond JL, Riviere JE, Duckett WM, Atkins CE, JerniganAD, Rikihisa Y, Spurlock SL. Cardiovascular effects and fatalities associated with intravenous administration of doxycycline to horses and ponis. Equine Vet J 1992;24:41-45.

137. Riond JL, Duckett WM, Riviere JE, Jernigan AD, Spurlock SL. Concerned about intravenous use of doxycyclinein horses. J Am Vet Med Assoc 1989;195:846847. 
138. Andersson G, Ekman L, Mansson I, Persson S, Rubarth S, Tufvesson G. Lethal complications following administration of oxytetracyclin in the horse. Nord Vet Med 1971;23:9-22.

139. Owen RA. Post stress diahrroea in the horse. Vet Rec1975;96:267-270.

140. Edwards DJ, Love DN, Raus J. The nephrotoxic potential of neomycin in the horse. Equine Vet J 1989;21:206-210.

141. Riviere JE, Spoo JW. Aminoglycoside antibiotics. In: Adams HR, editor. Veterinary pharmacology and therapeutics. $7^{\text {th }}$ ed. Ames (Io): Iowa State University Press, 1995:797-819.

142. Bennett WM, Plamp CE, Gilbert DM, Parker RA, PorterGA. The influence of dosage regimen on experimental gentamicin nephrotoxicity: dissociation of peak serum levels from renal failure. J Infect Dis 1979;140:576-580.

143. Nostrandt AC, Pedersoli WM, Marshall AE, Ravis WR,Robertson BT. Ototoxic potential of gentamicin in ponis. Am J Vet Res 1991;52:494-498.

144. Sweeney RW, Divers TJ, Rossier Y. Disposition of gentamicin administered intravenously to horses with sepsis. J Am Vet Med Assoc 1992;200:503-506.

145. Tobin T. Pharmacology review: streptomycin, gentamicin and the aminoglycoside antibiotics. J Equine Med Surg 1978;4:206-212.

146. Riviere JE, Coppoc GL, Hinsman EJ, Carlton WW, Traver DS. Species-dependent gentamicin pharmacokinetics and nephrotoxicity in the young horse. Fund Appl Toxicol 1983;3:448-457.

147. Hinchcliff KW, Mcguirk SM, Macwilliams PS, Cooley AJ. Phenolsulfophthalein pharmacokinetics and renal morphological changes in adult pony mares with gentamicin-induced nephrotoxicosis. Am J Vet Res 1989;50:1848-1853.

148. Schumacher J, Duran S, Wilson R. The effect of diet ongentamicin-induced nephrotoxicity in the horse. J Vet Intern Med 1989;3:136.

149. Spoo JW, Riviere JE. Chloramphenicol, macrolides,lincosamides, fluoroquinolones, and miscellaneous antibiotics. In: Adams HR, editor. Veterinary pharmacology and therapeutics. $7^{\text {th }}$ ed. Ames (Io): Iowa State University Press, 1995:820-854.

150. Raisbeck MF, Holt GF, Osweiler GD. Lincomycinassociated colitis in horses. J Am Vet Med Assoc 1981;179:362-363.

151. Vancustem PM, Babish JG, Schwark WS. The fluoroquinolone antimicrobials: structure, antimicrobial activity, pharmacokinetics, clinical use in domestic animals and toxicity. Cornell Vet 1990;80:173-186.

152. Langston VC, Sedrish S, Boothe DM. Disposition of single-dose oral enrofloxacin in the horse. J Vet Pharmacol Ther 1996;19:316-319.

153. Mansmann RA. Antimicrobial therapy in horses. Vet Clin North Am 1975;5:81-97.

154. Gronwall R, Brown MP, Merritt AM, Stone HW. Body fluids concentrations and pharmacokinetics of chloramphenicol given to mares intravenously or by repeated dosage. Am J Vet Res 1986;47:2 591-2 595.

155. Page SW. Cloramphenicol 3. Clinical pharmacology of systemic use in the horse. Austr Vet J 1991;68:5-8. 
156. Sweeney RW, Sweeney CR, Weiher J. Clinical use of metronidazole in horses: 200 cases (1984-1989). J Am Vet Med Assoc 1991;198:1 045-1 048.

157. Keck G. Toxicite et effets indesirables des anti-inflammatoires non-steroidiens. Etude des cas rapportes au CNITV (Centre National d'Informations Toxicologiques Veterinaires). Rec Méd Vét 1992;168:615-620.

158. Auer DE, Ng JC, Seawright AA. Superoxide production by stimulated equine polymorphonuclear leukocytes - inhibition by anti-inflammatory drugs. J Vet Pharmacol Ther 1990a;13:59-66.

159. Lees P, Higgins AJ. Clinical pharmacology and therapeutic uses of non-steroidal anti-inflammatory drugs in the horse. Equine Vet J 1995;17:83-96.

160. Boothe DM. The analgesic-antipyreticantiinflammatory drugs. In: Adams HR, editor. Veterinary pharmacology and therapeutics. $7^{\text {th }}$ ed. Ames (Io): Iowa State University Press, 1995:432-449.

161. Lees P, May SA. Inflammation and anti-inflammatorydrugs. In: Andrews AH, Blowey RW, Boyd H, Eddy RG, editors. Bovine medicine. Diseases and husbandry of cattle. Oxford (UK): Blackwell Scientific Publications, 1992:843-863.

162. Murray MJ. Nonsteroidal antiinflammatory drugs toxicity.In: Smith BP, editor. Large animal internal medicine. St. Louis (Mo): The C.V. Mosby Co., 1990;665-668.

163. Traub-Dargatz JL. Non-steroidal anti-inflammatorydrug-induced ulcers. Proceedings of the 33rd. Annual Convention of the American Association of Equine

164. Practitioners; 1987 November 29 to December 2; New Orleans (Lo). Lexington (Ke): American Association of Equine Practitioners, 1988;129-132.

165. MacAllister CG, Taylor-MacAllister C. Treating and preventing the adverse effects of nonsteroidal antiinflammatory drugs in horses. Vet Med 1994;89:241-246. 165. MacAllister CG, Morgan SJ, Borne AT, Pollet AR. Comparison of adverse effects of phenylbutazone, flunixin meglumine, and ketoprofen in horses. J Am Vet Med Assoc 1993;202:71-77.

166. Samperio JC. Efectos de la administración crónica dedipirona sobre algunas constantes hematológicas en equinos (tesis de licenciatura). México (DF) México: Facultad de Medicina Veterinaria y Zootecnia. UNAM, 1985.

167. Hunt JM, Lees P, Edwards GB. Suspected non-steroidal anti-inflammatory drug toxicity in a horse. Vet Rec 1985;117:581-582.

168. Skarda RT. Antagonist effects of atipemazole on epidurally administred detomidine-induced sedation analgesia and cardiopulmonary depression in horses. J Vet Anaesth 1991;Special Suppl:79-81.

169. Longo F, Autefage A, Bayle R, Keister M, Van Gool F. Efficacy of a non-steroidal anti-inflammatory, ketogen 10\% (ketoprofen) in the treatment of colic in horses. J Equine Vet Sci 1992;12:311-315.

170. Galván JC. Usos terapéuticos y propiedades farmacológicasde la fenilbutazona en equinos. Estudio recapitulativo (tesis de licenciatura). México (DF) México: Facultad de Medicina Veterinaria y Zootecnia. UNAM, 1983.

171. Barragry TB. Veterinary drug therapy. Philadelphia: Lea \& Febiger, 1994. 
172. Kallings P. Nonsteroidal anti-inflammatory drugs. Vet Clin North Am Equine Pract 1993;9:523-541.

173. Karcher LF, Dill SG, Anderson WI, King JM. Right dorsal colitis. J Vet Intern Med 1990;4:247-253.

174. Simmons TR, Gaughan EM, Ducharme NG, Dill SG, King JM, Anderson WI. Treatment of right dorsal ulcerative colitis in a horse. J Am Vet Med Assoc 1990;196:455-458.

175. Trailovic D, Litricin V, Trailovic R, Petrujkic T, KrsticV. Osvrt na neke stetne efekte fenilbutazona u sportskih konja. Vet Glasn 1989;43:635-639.

176. Meschter CL, Cummings JF, Krook L, Maylin GA.Phenylbutazone-induced microascular lesions in the gastric mucosa of horses. Toxic Pathol 1987;15:371-372.

177. Meschter CL, Gilbert M, Krook L, Maylin G, Corradino R. The effects of phenylbutazone on the morphology and prostaglandin concentrations of the pyloric mucosa of the equine stomach. Vet Pathol 1990;27:244-253.

178. Meschter CL, Krook L, Maylin GA. Phenylbutazone induced microvascular lesions in the gastrointestinal mucosa of horses. Equine Vet J 1989;7(Suppl):141.

179. Maitho TE, Lees P, Taylor JB. Absorption and pharmacokinetics of phenylbutazone in Welsh Mountain ponis. J Vet Pharmacol Ther 1986;9:26-39.

180. Tobin T, Chay S, Kamerling S, Woods WE, Weckman TJ, Blake JW, Lees P. Phenylbutazone in the horse: a review. J Vet Pharmacol Ther 1986;9:1-25.

181. Mcdonnell SM, Love CC, Pozor MA, Diehl NK. Phenylbutazone treatment in breeding stallions: preliminary evidence for no effect on semen or testicular size. Theriogenology 1992;37:1225-1232.

182. Macallister CG. Nonsteroidal anti-inflammatory drugs: their mechanism of action and clinical uses in horses. Vet Med 1994;89:237-240.

183. Crisman MV, Sams RA, Irby MH. The disposition ofphenylbutazone in lactating mares and its effect on nursing foals. Proceedings of the $36^{\text {th }}$ Annual Convention of the American Association of Equine Practitioners; $1990 \mathrm{Au}-$ gust 24-26; Lexington (Ke). Lexington (Ke): American Association of Equine Practitioners, 1990:127-131.

184. Crisman MV, Wilcke JR, Sams RA, Gerken DF. Concentrations of phenylbutazone and oxyfenbutazone in post-parturient mares and their neonatal foals. J Vet Pharmacol Ther 1991;14:330-334.

185. Zicker SC, Brumbaugh GW. Effects of phenylbutazone on glucose tolerance and on secretion of insulin in healthy geldings. Am J Vet Res 1989;50:743-746.

186. Read WK. Renal medullary crest necrosis associated with phenylbutazone therapy in horses. Vet Pathol 1983;20:662-669.

187. Auer DE, Ng JC, Seawright AA. Copper salicylate and copper phenylbutazone as topically applied antiinflammatory agents in the rat and horse. J Vet Pharmacol Ther 1990;13:67-75.

188. Traub-Dargatz JL, Bertone JJ, Gould DH, Wrigley RH, Weiser MG, Forney SD. Chronic flunixin meglumine therapy in foals. Am J Vet Res 1988;49:7-12. 
189. Geor RJ, Petrie L, Papich MG, Rousseaux C. The protective effects of sucralfate and ranitidine in foals experimentally intoxicated with phenylbutazone. Can J Vet Res 1989;53:231-238.

190. Held JP, Daniel GB. Use of nonimaging nuclear medicine techniques to assess the effect of flunixin meglumine on effective renal plasma flow and effective renal blood flow in healthy horses. Am J Vet Res 1991;52:1 619-1 621.

191. Carrick JB, Papich MG, Middleton DM, Naylor JM, Townsend HGG. Clinical and pathological effects of flunixin meglumine administration to neonatal foals. Can J Vet Res 1989;53:195-201.

192. Carrick JB, Papich MG, Middleton DM. Effets cliniqueset anatomopathologiques de la flunixine meglumine dans le traitment de poulains nouveau-nes. Action Vét 1991;7(Suppl. 1186):10-12.

193. Helmy MM, Soliman FA, Ragab AM, Aggag BI. Effectsof flunixin meglumine (Finadyne) on blood of horses in the treatment of some common inflammatory conditions. Egypt J Comp Pathol Clin 1991;4:113-133.

194. Longo F, Autefage A, Bayle R, Van Gool F. Efficacite deketoprofene dans les affections musculo-squelettiques du cheval. Bull Mens Soc Vét Prat Fr 1990;74:349-364,366-367.

195. Gregoricka MJ, Sutherland SF, Dedrickson BJ, BuschKR. Assessment of the intramuscular administration of ketoprofen. Equine Pract 1990;12:15-22.

196. De Jong RH. 1995 Gaston Labat lecture. Ropivacaine. White knight or dark horse? Reg Anesth 1995;20:474481.

197. Doonan GR, Brown CM, Mullaney TP, Brooks DB, Ulmanis EG, Slanker MR. Monensin poisoning in horses - an international incident. Can Vet J 1989;30:165-169.

198. Hanson LJ, Eisenbeis HG, Givens SG. Toxic effects oflasolacid in horses. Am J Vet Res 1981;42:456-461.

199. Novilla MN. The veterinary importance of the toxic syndrome induced by ionophores. Vet Hum Tox 1992;34:66-70.

200. Amend JF, Mallos FM, Wren WB, Ramos AS. Equinemonensis toxicosis: some experimental clinicopathologic observations. Comp Cont Educ Pract Vet 1980;2:5173-5183.

201. Matsuoka T. Evaluation of monensin toxicity in the horse. J Am Vet Med Assoc 1976;169:1 098-1 100.

202. Buck WB, Osweiler GD, Van Gelder GA. Clinical anddiagnostic veterinary toxicology. $3^{\text {rd }}$ ed. Dubuque (Io): Kendall/Hunt, 1985.

203. Muylle E, Vandenhende C, Oyaert W, Thoonen H, Vlaeminck K. Delayed monensin sodium toxicity in horses. Equine Vet J 1981;13:107-108.

204. Di Pietro JA, Klei TR, French DD. Contemporarytopics in equine parasitology. Comp Cont Edu Pract Vet 1990;12:713-716,718-721.

205. Bello TR. Controlled test evaluation of the benzimidazole anthelmintic VET 220-S alone or with trichlorfon treatment against naturally acquired gastrointestinal parasites in ponis. Am J Vet Res 1991;52:566-569.

206. Adams JG, Trim CM. Cardiovascular effects recorded in horses during anaesthesia after treatment with trichlorfon. Res Vet Sci 1989;47:164-169. 
207. Auer DE, Seawright AA, Pollit CC, Williams G. Illness in horses following spraying with amitraz. Austr Vet J 1984;61:257-259.

208. Hugnet C, Cadoré JL. Toxicologie de l'amitraz chez lecheval. Prat Vet Equine, 1995;27:139-141.

209. Roberts MC, Argenzio A. Effects of amitraz, severalopiate derivates and anticholonergic agents on intestinal transit in ponis. Equine Vet J 1986;18:256-260.

210. Roberts MC, Seawright AA. Amitraz induced large intestinal impaction in the horse. Austr Vet J 1979;55:553-554.

211. Smith SEG. Treatment of mange in horses. Vet Rec 1994;134:508.

212. Roberts MC, Seawright AA. Experimental studies of drug-induced impaction colic in the horse. Equine Vet J 1983;15:222-228.

213. Bhadwal MS, Singh J, Singh R. Treatment of equinetrypanosomiasis. Centaur Mylapore, 1995;11:91.

214. Harkins JD, Carney JM, Tobin T. Clinical use and characteristics of the corticosteroids. Vet Clin North Am Equine Pract 1993;9:543-562.

215. Mcdonnell AM, Watson ED. The effects of dexamethasone phosphate on mares with exprimentally-induced endometritis. J Equine Vet Sci 1993;13:202-206.

216. Mcilwraith CW. Diseases of joints, tendons and related structures. In: Stashak TS, editor. Adams' lameness in horse. Philadelphia: Lea \& Febiger, 1987:364-366.

217. Santisteban JM, Gómez-Villamandos R, Avila-JuradoI. Empleo preoperatorio de dexametasona 21isonicotinato como profilaxis antiinflamatoria en caballos sometidos a diferentes intervenciones quirúrgicas. Med Vet 1994;11:481-488.

218. Cohen ND, Carter GK. Steroid hepatopathy in a horse with glucocorticoid-induced hyperadrenocorticism. J Am Vet Med Assoc 1992;200:1682-1684.

219. Fahmy LS, Hegazzy AA, Fahmy AS, El Hamied MAA,Shamaa AA, Schimke E. Comparison of corticosteroids and dimethylsulfoxide treatment in chemically induced arthritis in horses. Vet Med J Giza 1994;42:175-188.

220. O'Conner JT. The untowards effects of the corticosteroids in equine practice. J Am Vet Med Assoc 1968;153:1 614-1 617.

221. Slone DE, Purohit RC, Ganjam VK, Lowe JL. Sodiumretention and cortisol (hydrocortisone) suppression caused by dexamethasone and triancinolone in equids. Am J Vet Res 1983;44:280-283.

222. Toutain PL, Brandon RA, De Pomyers H. Dexamethasone and prednisolone in the horse: pharmacokinetics and action on the adrenal gland. Am J Vet Res 1984;45:1750-1756.

223. Beech J. Tumors of the pituitary gland (pars intermedia) In: Robinson EN, editor. Current therapy in equine medicine. $2^{\text {nd }}$ ed. Philadelphia: W.B. Saunders Co., 1987:182-185.

224. Hackett RP. Intra-articular use of corticosteroids in the horse. J Am Vet Med Assoc 1982;181:292-294.

225. Nizolek DJH, White KK. Corticosteroids and hialuronic acid treatments in equine degenerative joint disease. A review. Cornell Vet 1981;71:355-375. 
226. Chunekamrai S, Krook LP, Lust G, Maylin GA. Changes in articular cartilage after intra-articular injections of metylprednisolone acetate in horses. Am J Vet Res 1989;50:1733-1741.

227. Trotter GW, Mcilwraith CW, Gabel AA, Nordin RW, Wrigley RH, Lamar CH. Effects of intra-articular administration of metylprednisolone acetate on normal equine articular cartilage. Am J Vet Res 1991;52:83-87.

228. Owen RR, Marsh JA, Hallet FR, Lumsden JH, Johnson J. Intraarticular corticosteroid and excercise-induced arthropathy in a horse. J Am Vet Med Assoc 1984;184:302-308.

229. Redhun WC, Hacker DV, Murphy CJ. Calcific bandkeratopathy in horses. Comp Cont Edu Equine Pract 1993;10:1 402-1 408.

230. Fregin GF. The equine electrocardiogram with standardized body and limb positions. Cornell Vet 1982;72:304-324.

231. Hilwing RW. Cardiac arrythmias in the horse. J AmVet Med Assoc 1977;170:153-163.

232. Adams HR. Antiarrhythmic agents. In: Adams HR,editor. Veterinary pharmacology and therapeutics. $7^{\text {th }}$ ed. Ames (Io): Iowa State University Press, 1995:482-500.

233. Bouckaert S, Voorspoels J, Vandenbossche G, Deprez P, Remon JP. Effect of drug formulation and feeding on the pharmacokinetics of orally administrated quinidine in the horse. J Vet Pharmacol Ther 1994;17:275-278.

234. Bonagura JD, Muir WW. The cardiovascular system.In: Muir WW, Hubbell JAE, editors. Equine anesthesia. Monitoring and emergency therapy. St. Louis (Mo): Mosby Year Book, 1991:39-104.

235. Harding SA, Jones RM. Intercurrent medication. In: Aitkenhead AR, Jones RM, editors. Clinical anaesthesia. New York: Churchill Livingstone, 1996:79-105.

236. Hilwig RW. Cardiac arrythmias. In. Robinson EN,editor. Current therapy in equine medicine. $2^{\text {nd }}$ ed. Philadelphia: W.B. Saunders Co., 1987:152-163.

237. Mcguirk SM, Shaftoe S, Lunn DP. Diseases of the cardiovascular system. In: Smith BP, editor. Large animal internal medicine. St. Louis (Mo): The C.V. Mosby Co., 1990:454-488.

238. Reef VB, Reimer JM, Spencer PA. Treatment of atrial fibrillation in horses: new perspectives. J Vet Intern Med 1995;9:57-67.

239. Ellis EJ, Ravis WR, Malloy M, Duran SH, Smyth BG. The pharmacokinetics and pharmacodynamics of procainamide in horses after intravenous administration. J Vet Pharmacol Ther 1994;17:265-270.

240. Coyle JD, Lima JJ. Procainamide. In: Evans WE, Schentag JJ, Jusko WJ, Harrison H, editors. Applied pharmacokinetics. Spokane (Mo): Applied Therapeutics Inc., 1986:628-711.

241. Boothe DM. Drugs affecting the respiratory system. In: Adams HR, editor. Veterinary pharmacology and therapeutics. $7^{\text {th }}$ ed. Ames (Io): Iowa State University Press, 1995:1091-1104. 
242. Adams HR. Adrenergic agonists and antagonists. In: Adams HR, editor. Veterinary pharmacology and therapeutics. $7^{\text {th }}$ ed. Ames (Io): Iowa State University Press, 1995:87-113.

243. Adams HR. Digitalis and vasodilator drugs. In: AdamsHR, editor. Veterinary pharmacology and therapeutics. $7^{\text {th }}$ ed. Ames (Io): Iowa State University Press, 1995:451-481.

244. Sumano LH, Navarro J, Gutierrez J. Lethal synergismbetween meperidine and fentanyl with propanolol and its reversal by naloxone. Joint Meeting of the

245. Asociación Mexicana de Farmacología-West Pharmacology Society Texas; VII National Conference of Pharmacology; 1983 July 4-7; Puerto Vallarta (Jalisco) México. México (DF): Asociación Mexicana de Farmacología, 1983:123.

246. Staudacher G. Individual glycosid treatment by means ofserum concentration determination in cardiac insufficency in horses. Berl Muench Tieraerzt Wchschft 1989;102:1-3.

247. Button C, Gross DR, Johnston JT, Yakatan GJ. Digoxin pharmacokinetics, bioavailability, efficacy, and dosage regimens in the horse. Am J Vet Res 1980;41:1388-1395. 247. Guthrie AJ, Killen VM, Mulders SG, Grosskopf JFW. Use of cardiopulmonary flow index to evaluate cardiac function in Thoroughbred horses. J South Afr Vet Assoc 1991;62:43-47.

248. Erichsen DF, Aviad AD, Schultz RH, Kennedy TJ. Clinical efficacy and safety of clenbuterol $\mathrm{HCl}$ when administred to effect in horses with chronic obstructive pulmonary disease (COPD). Equine Vet J 1994;26:331-336.

249. Muir WW. Cardiovascular effects of dopexamine $\mathrm{HCl}$ in conscious and halothane-anesthetised horses. Equine Vet J 1992;24(Suppl. 11):24-299.

250. Moore BR, Hinchcliff KW. Heparin: a review of its pharmacology and therapeutic use in horses. J Vet Int Med 1994;8:26-35.

251. Duncan S, Meyers K, Reed S. Reduction of the red blood cell mass of horses: toxic effect of heparin anticoagulant therapy. Am J Vet Res 1983;46:2175-2178.

252. Mahaffey E, Moore J. Erythrocyte agglutination associated with heparin treatment in three horses. J Am Vet Med Assoc 1986;189:1478-1480.

253. Messer NT, Johnson PJ. Idiopathic acute hepatic disease in horses: 12 cases (1982-1992). J Am Vet Med Assoc 1994;204:1934-1937.

254. Geimer TR, Ekström PM, Ludders JW, Short CE, GleedRD. Cardiovascular effects of atropine in ponis. Vet Surg 1992;21:500-501.

255. Ducharme NG, Fubini SL. Gastrointestinal complications associated with the use of atropine in horses. J Am Vet Med Assoc 1983;182:229-231.

256. Ehrhardt EE, Lowe JE. Observer variation in equine abdominal auscultation. Equine Vet J 1990;22:182-85.

257. McLaughlin SA, Whitley RD, Gilger BC. Ophthalmicatropine in horses: is colic a serious problem? Equine Vet Educ 1991;3:94-96.

258. Gustafson SB, Mcilwraith CW, Jones RL. Comparison of the effect of polysulfated glycosaminoglycan, corticosteroids, and sodium hyaluronate in the potentiation of a subinfective dose of Staphylococcus aureus in the midcarpal joint of horses. Am J Vet Res 1989;50:2 014-2 017. 
259. Pell LH, Blythe LL, Lassen ED, Craig AM. Adverse effects of rapid intravenous DMSO administration in horses. J EquineVet Sci 1992;12:215-218.

260. Weiss DJ, Evanson OA, Geor RJ. The effects of furosemide and pentoxifylline on the flow properties of equine erythrocytes: in vitro studies. Vet Res Comm 1994;18:373-381.

261. Olsen SC, Coyne CP, Lowe BS, Pelletier N, Raub EM, Erickson HH. Influence of cytooxygenase inhibitors on furosemide induced hemodynamic effects during exercise in horses. Am J Vet Res 1992;53:1 562-1 567.

262. Harkins JD, Tobin T. Racing horses, nitroglycerin and exercise induced pulmonary haemorrhage (EIPH). Equine Vet J 1995;27:240-241.

263. Harkins JD, Lawrence LM, Hintz HF. Effect of supplemental sodium bicarbonate on equine performance. Comp Cont Educ Pract Vet 1994;16:200-207.

264. Gossett KA, French DD, Cleghorn B. Blood biochemical response to sodium bicarbonate infusion during sublethal endotoxemia in ponis. Am J Vet Res 1990;51:1 370-1 374.

265. Snow DH, Munro CD, Nimmo M. Effects of nandrolone phenylpropionate in the horse. 2. General effects in animals undergoing training. Equine Vet J 1982;14:224-228.

266. Maher JM, Squires EL, Voss JL, Shideler RK. Effect of anabolic steroids on reproductive function of young mares. J Am Vet Med Assoc 1983;183:519-524.

267. Squires EL, Voss JL, Maher JM, Shideler RK. Fertility of young mares after long-term anabolic steroid treatment. J Am Vet Med Assoc 1985;186:583-587.

268. Snow DH. Anabolic steroids. Vet Clin North AmEquine Pract 1993;9:563-576.

269. Blanchard TL. Some effects of anabolic steroidsespecially in stallions. Comp Cont Edu Pract Vet 1982;7:372-380.

270. Errecalde JO, Button C, Mülders MSG. Some dynamic and toxic effects of theophylline in horses. J Vet Pharmacol Ther 1985;8:320-327.

271. Schryver HF, Hintz HF. Vitamins. In: Robinson EN,editor. Current therapy in equine medicine. $2^{\text {nd }}$ ed. Philadelphia: W.B. Saunders Co., 1987:405-412.

272. Harrington DD, Page EH. Acute vitamin D3 toxicosis in horses: case reports and experimental studies of the comparative toxicity of vitamins D2 and D3. J Am Vet Med Assoc 1983;182:1358-1369.

273. Divers TJ. Equine renal system. In: Smith BP, editor.Large animal internal medicine. St. Louis (Mo): The C.V. Mosby Co., 1990:872-887.

274. Divers TJ. Toxic diseases. In: Colahan PT, Mayhew IG,Merrit AM, Moore JN, editors. Equine medicine and surgery. Vol 2. $2^{\text {nd }}$ ed. Goleta (Ca): American Veterinary Publications Inc., 1991:1553-1555.

275. Gray A. Suspected adverse reactions surveillance scheme for veterinary medicines (SARSS). Equine Vet Educ 1995;7:112-114. 